\title{
Considering technology within the UN climate change negotiations
}

\author{
Morgan Bazilian ${ }^{\mathrm{a}}$, Heleen de Coninck ${ }^{\mathrm{b}}$, Mark Radka ${ }^{\mathrm{c}}$, \\ Smita Nakhooda ${ }^{d}$, William Boyd ${ }^{\mathrm{e}}$, lain MacGill ${ }^{\mathrm{f}}$, Amal-Lee Amin ${ }^{\mathrm{g}}$, \\ Fredrik von Malmborg ${ }^{h}$, Jukka Uosukainen ${ }^{i}$, Rob Bradley ${ }^{d}$, and \\ Rick Bradley
}

${ }^{\mathrm{a} D e p a r t m e n t}$ of Communications, Energy and Natural Resources, Dublin, Ireland

${ }^{b}$ Energy Research Centre of the Netherlands, Amsterdam, Netherlands

'UNEP Division of Technology, Industry and Economics, Paris, France

'World Resources Institute, Washington DC, USA

eUniversity of Colorado, School of Law, Boulder CO, USA

fUniversity of New South Wales, Sydney, Australia

Inter-American Development Bank, Washington DC, USA

${ }^{h}$ Linköping University, Department for Management and Engineering, Sweden

'Ministry of the Environment, Helsinki, Finland

'International Energy Agency, Paris, France 


\title{
Acknowledgements
}

We would like to thank Hugh Outhred (UNSW), Stefan Heck (McKinsey), Shane Tomlinson (E3G), and Fabrizio Tulej (EC) for their insights and contributions. Reviews by Andrew Higham and Jos Sijm (ECN) were very useful. Support from the Dutch Ministry of Economic Affairs is also recognised.

\begin{abstract}
The treatment of technology within the UNFCCC negotiation process has moved from a relatively marginal subject to one of central importance, and is likely to be critical to ensuring a successful outcome at COP15. The development, deployment and transfer of low-carbon technologies, and overcoming related investment challenges, is, however, an issue considerably wider than the remit and scope of the UNFCCC. Hence there is a need to understand how cooperative action on technology under the Convention can be most effective. The existing UNFCCC technology framework would need to be significantly refined and augmented in order to appropriately address the scale and pace of the low-carbon technology implementation challenge. This paper considers the contours of an enhanced technology framework that could contribute to a future climate change agreement. In doing so, it synthesises aspects of the relevant literature and creates a link to the decision-making process of the UNFCCC.
\end{abstract}

Disclaimer: The content and views expressed in this paper are not attributable to national or organisational positions in the climate negotiations or elsewhere. All of the authors contributed in their personal capacities.

Corresponding Author: Morgan Bazilian, 29-31 Adelaide Rd., Dublin 02, Ireland; Phone: +353 1678 2026; E-mail: Morgan.Bazilian@dcenr.gov.ie 


\section{Contents}

List of figures $\quad 4$

1. Introduction 5

2. A literature review of technology and climate change 9

2.1 Technology Transfer, technological change and innovation 10

$\begin{array}{lll}2.2 & \text { Models, tools and scenarios for technology } & 13\end{array}$

3. Technology in the climate negotiations 18

$\begin{array}{ll}3.1 & \text { Technology in the UNFCCC context } \\ 3.2 & 18\end{array}$

$\begin{array}{lll}3.2 & \text { Technology as a design feature of a 'deal' } & 19\end{array}$

$\begin{array}{lll}3.3 & \text { Technology requires a differentiated approach } & 21\end{array}$

4. Priority elements for an enhanced treatment of technology 24

4.1 Enabling environments 24

4.2 Intellectual Property Rights 26

4.3 Trade issues 28

4.4 Technology partnerships, agreements and sectoral approaches 29

4.5 Sustainable Development Policies and Measures 31

4.6 Finance for technology 32

4.6.1 The scale of the investment opportunity 33

4.6.2 Specific financial barriers in developing countries 35

4.6.3 Gaps and instruments $\quad 36$

5. A conceptual framework 40

5.1 Criteria for a conceptual technology framework 40

5.2 Contours of a conceptual technology framework 41

5.3 Measuring Success 44

6. Conclusions 46

References $\quad 48$ 


\section{List of figures}

Figure 2.1 Vatenfall/McKinsey MACC in $2030 \quad 15$

Figure 2.2 IEA Technology portfolio for the Blue Map scenario 16

Figure 2.3 Categorisation of power sector technologies and their mitigation potential 16

Figure 2.4 EE technologies needs in buildings and residential sectors 17

Figure 3.1 Renewable energy penetration by technology and region 22

Figure 3.2 Penetration of new technologies by income level 23

Figure 4.1 Enabling environments schematic 25

Figure 4.2 Overall technology finance needs 33

Figure 4.3 Scale of public technology development support needed 34

Figure 4.4 Sustainable energy investment by category 2004-2007 35

Figure 4.5 Technology development life cycle schematic 37

Figure 5.1 Conceptual technology framework 44 


\section{Introduction}

Technology issues have become central to the post-2012 climate change policy debate. De Boer (2008) reinforces this, "There is an urgent need to discover what effective language a Copenhagen agreement needs to entail in order to unleash the full potential of technology.” Drawing from existing literature on technology and climate change, this paper aims to inform consideration of technology within the confines of the United Nations Framework Convention on Climate Change (UNFCCC) negotiations. We consider elements of an enhanced framework within a potential agreement at the $15^{\text {th }}$ Conference of the Parties (COP) in Copenhagen. It is recognised that the final form of that agreement need not attempt to encompass all aspects of mitigation and adaptation technology issues, and that an approach based on adaptive learning and adjustment is more pragmatic.

Our technological systems, critically our energy systems, lie at the heart of the climate change challenge as essential contributors to social welfare and the principal source of anthropogenic greenhouse gas emissions. The term technology in this paper generally refers to low-carbon energy technologies that face technological, institutional or economic barriers. Primarily, these include Renewable Energy (RE), Energy Efficiency (EE), Carbon Capture and Storage (CCS) and small-scale, highly efficient fossil-fuel options ${ }^{1}$. Although this paper focuses on technologies for mitigation, adaptation technologies, which are often fundamentally different from mitigation ones, may still benefit from similar guiding principles as those introduced in this paper.

Technology is embedded in many aspects of the Convention. As a subject of discussion under the UNFCCC, technology has moved from a relatively marginal topic to a central one ${ }^{2}$. The Bali Action Plan (BAP) (1/CP.13) $)^{3}$ continued this transition by including technology as one of the four 'building blocks' of a future agreement, in addition to mitigation, adaptation and finance. The rise of technology on the negotiation agenda can be understood as a response to:

- The realisation that a significant shift in the pace and scale of the development, deployment, transfer and implementation of low-carbon technologies will be required to meet stabilisation targets of 450 ppmv CO2-eq (IPCC, 2007). Most major studies on climate mitigation reach similar conclusions in this regard: a suite of technologies is required, the necessary principal technologies required have been largely identified, and the rough scale of deployment to mitigate climate change has been analysed (e.g. Stern, 2006; IPCC, 2007; IEA, 2008; McKinsey, 2008). The question is how to rapidly take these technologies from niche applications to widespread deployment so that can displace our present high-carbon energy technology systems.

- Recognition that any emission reduction agreement that cannot be legally enforced is likely to create strong free-rider incentives (Fisher, 1996; Stavins, 1997; Hoel, 1999; Aldy, 2001; Kemfert, 2003; Finus, 2006; Weikard, 2006). Targets have meaning only with respect to the measures that are undertaken in order to comply with them. A carbon price signal is vital for technology change. Indeed the goals of the carbon price signal as a result of implementation of flexibility mechanisms in carbon markets is primarily focused towards implementing lowcarbon technologies. However, it is only one element of a suite of interventions required; a necessary but insufficient condition. By strengthening reciprocity and thus compliance, the

1 We regard nuclear power as conventional technology, although it has low emissions and significant barriers to deployment.

2 This is an anecdotal observation referring to the attention focused on Article 4.5 of the Convention as opposed to emissions reductions targets which have gained a central place in the Kyoto Protocol. Note that the Berlin Mandate of 1995 identified two possible paths forward - 'Common policies and measures' which would certainly have focussed on technology outcomes, or 'Quantified emission limitation and reductions objectives.' The choice of emissions targets without adequate attention to complementary policies and measures might be argued to have been sub-optimal from a technology perspective.

3 All COP decisions are available on: http://www.unfccc.int. 
effective treatment of technology would be an opportunity to provide for a more robust (scientifically and economically) and acceptable (politically and socially) Copenhagen Agreement4.

- The understanding that all of the four building blocks are intricately linked and interdependent, and that technology plays a significant role in all of them.

Although the final shape of a future international climate change regime is yet to be negotiated, it is interesting to note that the BAP has broadened the scope of the technology discussions under the UNFCCC; from focusing historically on technology transfer from industrialised to developing countries to covering aspects of international collaboration on technology development, deployment and diffusion. This is a necessary development since the overall challenge is to stimulate wide-scale, global adoption of a suite of appropriate technologies that provide deep emission reductions5. Thus, wider 'systems' issues need to be addressed in any viable technology framework:

- Many of the technologies required for climate change mitigation are now well understood, and some are being commercially deployed, thus an over-reliance on research and development (R\&D) policies will not alone bring forth the required shifts in investment patterns.

- Growth of some renewable energy technologies has been exponential. REN21 (2008) shows average annual PV growth (2002-2006) at 60\%, wind at about 25\%. Although this growth comes from a very low base (IEA, 2004), it is an important signal of shifts in energy sector investment decisions6. Renewable energy technologies still require continued and significant innovation in the overall energy system within which they must be embedded to achieve sufficient levels of market penetration.

- All low-carbon technologies require new models of regulation, business, and investment in infrastructure that are consistent with the prevailing market economy. Specific technologies (hardware) are only one part of the deployment challenge; system integration (including all aspects of successful project management) needs to be addressed coherently.

- Because of the long-term nature of investment in the energy sector, there are certain 'decision windows' that allow for significant impacts. Short-term action is urgently needed to avoid 'technological lock-in' apparent in our present energy system and achieve consistency with long-term goals (Foxon, 2002). Often economic models and the short-term focus of national budgets do not appropriately price these long-term benefits, and rather recommend a different approach to government spending.

- The process of technology innovation is inherently uncertain. Technology frameworks need to be robust against the possible failure of some technologies, and adaptable to respond to the potential rapid emergence and success of others.

- Public sector financing will not be sufficient to meet the scale of the challenge (UNFCCC, 2007). Rather, it should be designed to effectively leverage and channel private investment7 towards climate change mitigation.

This paper recognises that the area of technology is considerably wider than the remit and influence of the UNFCCC. Specifically, in the energy sector the UNFCCC influence is mostly apparent through the various forms of carbon pricing, or more directly through GEF-type interventions in the developing world. The existing UNFCCC technology framework has many appro-

4 Even under a conceivable non-cooperative outcome (i.e. no deal on binding emissions reductions targets), a technology agreement of some nature may prove to be part of a viable agreement.

5 In fact, the definition of technology transfer related to climate change proposed by the IPCC (2000) accounts for such a broad focus. It is the discussions on technology transfer under the UNFCCC that so far have been rather narrow.

6 IEA (2008) shows RE as the $2^{\text {nd }}$ largest source of electricity after coal soon after 2010.

7 'Private investment' as used here means investment that does not come from government sources. It includes, then, sources such as individual households, small firms and large corporations. 
priate elements that can be augmented and refined in a new agreement ${ }^{8}$. Importantly, the technology block in the Convention may be able to 'ground' key elements of the BAP (1/CP.13): sectoral approaches, the concept of measurable reportable and verifiable (MRV) (Guay et al., 2008), and the principle of common but differentiated responsibilities and respective capabilities (Article 3.1 of the UNFCCC). Some guiding principles for this work include:

- There is a need to consider approaches appropriate to various technology distinctions such as: specific market failures, the stage of technical maturity, the type of energy service market (electricity, heat, and transport), sectors, scalability, wider sustainability implications, and the scale and nature of the specific financial constraints. Each of these distinct categories will need to be supported by appropriate tools and interventions (a 'toolbox').

- The tools themselves will also need to differ significantly across regions and countries to be attractive and effective. Some countries, particularly least developed countries (LDCs), will require significantly larger and fundamentally different support programmes with greater emphasis on institutional capacity-building. Many of the actions required have already been identified in Technology Needs Assessments (TNAs).

- Similar to the Kyoto Protocol and its Marrakesh Accords, any toolbox need not be implemented solely by one entity, or defined in detail within a Copenhagen agreement. However, its key elements will need to be recognised within a Copenhagen agreement to allow for further detailed elaboration and implementation after 2009.

- A body with a mandated technology oversight function within, or related to, the UNFCCC is likely to be necessary to codify actions undertaken by various countries, monitoring and verification, appropriate technical support, and possibly funds disbursal. This paper, however, will not address this 'institutional' issue in any depth, and will instead focus on the programmatic elements.

- A focus on creating appropriate conditions (enabling environments and building capacity) for implementation is likely to be the highest value-for-public-money intervention under the UNFCCC. (Technology hardware is often relatively straightforward making technical knowhow, the establishment of appropriate market conditions, and institutional capacity the key challenges for success.) This is, however, difficult to monitor and verify against direct impacts on mitigation. Creativity will be needed to make these measures an enticing incentive for countries participating in the negotiation process.

Finally, the opportunities (and not just the challenges) of wide deployment of low-carbon technologies must be emphasised in the tone and goals of the negotiations, especially in light of the current (late 2008) state of the financial markets. This is particularly true for many developing UNFCCC Parties, which are looking for economic development as a first priority, and for which these technologies can form an integral part of ensuring such a 'just transition' (UNEP, 2008d). It is also true for those developed countries that understand innovation and productivity as key components in preserving competitiveness, and consider the risk benefits of a diverse energy sector (Geels, 2004; Bazilian, 2008; McKinsey, 2008). As an example, UNEP (2008d) cites a figure of 2.3 million workers in the renewable energy (RE) sector today with enormous growth possibilities still to be realised (6.3 million in solar alone by 2030).

This paper reviews the sizeable technology and climate change literature in Chapter 2, discussing key issues of defining technology, technology innovation, technology transfer, and mitigation and technology scenarios. Chapter 3 considers the role of technology in the climate negotiations, beginning with the current UNFCCC context for technology, and then investigating its potentially attractive role in supporting climate policy efforts, and the need for a differentiated approach for making progress. The resultant priority elements of a conceptual technology framework are then described in Chapter 4 including trade issues, intellectual property implications, technology and sector agreements, sustainable development objectives and the critical

8 3/CP.13 in Annex 1(3) states, "The existing structure, five thematic areas of work, definitions and purpose under the current technology transfer framework contained in the annex to decision 4/CP.7 continue to provide a solid basis for implementing the provisions of Article 4, Paragraph 5, of the Convention.” 
role of financing. A menu of options for the concept is presented in Chapter 5. Some concluding considerations relevant to the UNFCCC negotiations are offered in Chapter 6. 


\section{A literature review of technology and climate change}

The key role that technology will play in meeting climate change targets and aspirations is clear (IPCC, 2007); the exact mechanisms to ensure delivery are not. Bruckner (2007) summarises the technology issue as, "...new innovative technology cooperation mechanisms will be required to both deploy existing technologies in emerging economies and develop and share new low carbon technologies...Such a response to the dangers of global climate change would induce a transition towards a truly sustainable global energy system as a glorious 'side effect' ${ }^{\text {,". }}$ As a basis for our elaboration of conceptual elements of a technology framework under the UNFCCC, this section reviews perspectives from the literature relevant for understanding technology and climate change, spanning a number of disciplines. Although diverse, the insights stemming from the literature serve as a fundamental input to our elaboration of possible elements for the enhanced treatment of technology in the UNFCCC.

IIASA (2007) places technology in a wider economic context, “Technology is the main driving force of productivity and economic growth. Historical studies attribute about half of economic growth to technological change and the other half to the combined effect of all other driving forces." Stern (2008) emphasises the key role of technology, and defines success as, "a competitive supply of low carbon technologies, declining rapidly in cost over time, resulting in the substitution away from higher-carbon alternatives in both production and consumption.”

The principal technologies that will be required to respond to climate change have been largely identified and exist in different stages of development from fundamental research through to fully commercial. The majority of barriers to low-carbon technology deployment, although complex, have been identified ${ }^{10}$. They can be classified generally as technical, regulatory, financial, behavioural, and political. These challenges to implementation are not limited to the technologies themselves but to wider systems considerations. An initial focus on governance and human and institutional capacity is required (Lundvall, 1992; OECD, 1997; Grubb, 2007). These aspects are in essence pre-cursors to, and a basis for, 'enabling environments' for effective technology development and implementation. As IEA (2001) reminds us, "Technology transfer is not simply about the supply and shipment of hardware... It is about the complex process of sharing knowledge and adapting technology to meet local conditions. It strengthens human and technological capacity in developing countries.” The issue of climate-related technology continues to become more complex given the progress of some rapidly developing countries, and the increasingly global nature of technology R\&D, demonstration, commercialisation, manufacture and deployment.

We note that the complexity of the issue of climate change technology, its inherent multidisciplinary requirements, and the associated uncertainties create communication and translation 'gaps'. The sheer volume of analysis and commentary (of varying quality and rigour), along with the use of different disciplinary vocabularies and analytical methodologies from economics to science to engineering, aggravates this problem. An example of where these gaps exist is the

9 We further address this concept in Section 3.2.

10 The barriers to technology implementation have been well documented. Brown (2007) identifies barriers to technology implementation (within the context of the large USA CCTP programme (2006)). The barriers are given schematically in categories such as cost effectiveness, fiscal, regulatory, statutory, intellectual property rights (IPR), and policy/infrastructure. Barriers were also identified by developing country Parties in their TNAs (UNFCCC, 2006b), and suggest different areas of emphasis than the US study, namely the lack of financial resources (related to a lack of investment, relatively high costs of capital, lack of appropriate incentives, and lowincomes leading to low ability to pay, etc.). Interestingly, IPR issues are the least frequently referred to barrier in developing country's TNAs. It is important to note that detailed studies of the functionalities of technological innovation systems reveal that even if barriers may be similar on a general level, they are usually very different in different countries or regions (e.g. Jacobsson and Laubner, 2006). 
discussion of low-carbon technology in the UNFCCC, where the typical national representation is from Ministries of Environment (rather than Ministries of Energy). Indeed, the details of the UNFCCC process related to technology are largely opaque to the energy sector in the developed world. The treatment of climate change as an environmental issue, and not an integrated energy, transport, or land-use issue further exacerbates these gaps both in the negotiations themselves and in their ability to incentivise specific actions. This situation may lead to sub-optimal or poorly designed public policy, which could have serious consequences in terms of both the effectiveness in achieving goals, and the efficiency with which this is done. We attempt to bridge some of these gaps by presenting insights from the literature in the following Section.

\subsection{Technology Transfer, technological change and innovation}

Part of the challenge for assessing technology issues for climate change is that almost all of our technologies have energy implications. The Fourth Assessment Report (AR4) of the IPCC (2007) considered hundreds of stabilisation scenarios for climate change. All of them require a portfolio of new energy supply and end-use technologies to be deployed. Technical progress continues to make our response to climate change more challenging through its impacts on economic growth and development of new energy consuming technologies, as well as offering potential solutions through new and improved low-carbon technologies. The volume and disciplinary diversity of literature that is therefore potentially relevant to understanding technology and climate change is vast (Martinot, 1997). It is important to ensure that the insights stemming from it serve as an appropriate basis for the design of a future climate agreement.

The IPCC (2000) sought to crystallise aspects of the UNFCCC Article 4(5) (and 4(1c)), beginning with a broad definition ${ }^{11}$ of technology transfer as, "a broad set of processes covering the flows of know-how, experience and equipment for mitigating and adapting to climate change amongst different stakeholders such as governments, private sector entities, financial institutions, non-governmental organizations (NGOs) and research/education institutions" that also, "comprises the process of learning to understand, utilize and replicate the technology, including the capacity to choose it and adapt it to local conditions and integrate it with indigenous technologies”. The literature spans a number of disciplines, including engineering, physics, economics and social science, law, and public policy. Technologists have studied disruptive technologies and incremental change in technology advancement in many sectors over the course of a century (e.g. Rip and Kemp, 1998).

Economic theory has long since recognised the role of technical innovations and organisational innovations for long-term economic growth. However, little emphasis was paid to the study of technical change until 1939 when Schumpeter proposed that economic growth and decline is attributed to the diffusion of successive technological revolutions. Building on Keynesian theories of business cycles, Schumpeter highlights the important effects of political instability, government policies and 'band-wagon' effects of the diffusion of new technologies, products, services and markets within fifty year cycles of boom and bust. Solow's (1957) paper further placed technology at the heart of economic analysis ${ }^{12}$ and economic growth. His impact traces through many of the most well known economists of the $20^{\text {th }}$ century including Arrow (1962), Nordhaus (1969), Fisher (1971), and others.

In the 1980s the theory was further revived through an extensive body of empirical and theoretical research often referred to as the Neo-Schumpeterian approach to the economics of innova-

\footnotetext{
11 Definitions of technology can be found in: Rosenberg (1976, 1982), Kranzberg (1986), Levine (1992), Ziman (1968), Dodgson and Bessant (1996), Heaton et al. (1994), Stiglitz (1999), Martinot et al. (1997), Grubler and Nakicenovic (1990, 1991), Robinson (1991), etc. Other sources for literature reviews are: Bozeman (2000), Reddy (1990), Jaffe et. al. (2001), IEA (2001) Kline (2004), Norberg-Bohm (2000), Philibert (2003, 2004, 2005, 2007) and Ockwell (2007).

12 Solow refers to the influence of technology on output per head in the second paragraph of his paper.
} 
tions. In 1982, Dosi introduced the concept of a 'technological paradigm', defined progress through scientific, technological and economic opportunities and trade-offs, and introduced the term 'technological trajectory' to describe the rate and direction of the technological advance. Perez (1983) adopted the Schumpeterian approach towards interpreting Kondratieff's 'longwaves' or cycles of economic booms and busts, claiming that technically and economically interrelated innovations not only influence industries but rather characterise the tendencies of the economy as a whole. Such 'techno-economic paradigms' (TEPs) are underpinned by changes in the dynamics of the relative cost-structure of all types of production. Once established a TEP becomes a 'technological regime' whereby the key technological innovation (that has driven that TEP) is an omnipresent influence in all activities of the economy. In considering the electricity industry, Perez argues that the trend for centralisation was driven by availability of lowcost steel for engineering a characteristic of the Third Kondratieff. The Fourth Kondratieff characteristics of mass production and low-cost oil further consolidated this structure, and so reducing possibilities for alternative routes.

This self-reinforcing nature of technological change has been referred to as 'path-dependency' (David, 1975), 'technological momentum' (Hughes, 1983), and 'technological lock-in' (Arthur, 1989; and Rosenberg, 1994). Hughes' focus on the momentum of the electricity system highlights how system closure may be achieved through: vertical integration of the industry; regulatory capture and stakeholder encouragement of conservative inventions and adoption of technologies that preserve the existing institutional arrangements (Hughes, 1989).

Similarly, a large body of theoretical literature has focused on the interactions between technology and society, how society shapes technology, and vice versa how technology may determine society (e.g. Winner, 1977, 1993; Pacey, 1983; Hard, 1993; Stirling, 1994; and Misa, 1994). Generally, this work also serves to highlight the importance of the institutional context in which technical systems are embedded.

When considering the current Fifth Kondratieff, which has been driven by information intensive and knowledge-management activities, new opportunities exist for delivering a technological shift towards a more balanced electricity system trajectory - that is more efficient and maximises use of resources in a way that is consistent with a low carbon economy (Amin, 2000). The opportunities may be particularly large for developing countries, which have yet to invest in resource-intensive infrastructure; a part of the technological cycle that particularly enhances technological lock-in. However, Perez (1983) and Freeman (1997) identify 'institutional inertia' as a constraint towards adoption of such new opportunities. Hence, for technological change to be effectively captured and managed in a way that is consistent with tackling climate change, the role of governments must be to create conducive institutional contexts (enabling environments). This will require setting and enforcing appropriate policies and regulations at the national level, and, through the UNFCCC and other international bodies (e.g. the WTO), establishing a conducive institutional context at the international level.

The economic literature has further informed the discussion of climate change technology towards more practical policy recommendations in several respects (e.g. Grubler, 1990, 1996, 1998, 1999; Alic, 2003, etc.). Tol (2001), Caplan (2003), Kemfert (2004), Copeland (2005), Ruffin (2005) and others focus research efforts on economic modelling of aspects (including game theory) of the climate change agreements and provide confirmation of conclusions already drawn by political scientists (Keohane, 1984; Martin, 1992) on rational actor behaviour, collective action problems and free-rider incentives in the context of international institutions. The treatment of endogenous technological change in energy and climate modelling, for example, attempts to formalise the application of that literature, and includes discussion of learning curves (Nakicenovic, 1997; Wene, 2003; ISET, 2004; Edenhofer, 2006; Jamasb, 2007; Pizer, 2007). Details of the technical aspects of learning by doing, learning curves, and a detailed overview of the innovation literature are found in Kohler (2006). General conclusions are that, although 'moving down the learning curve' will reduce costs of low-carbon technologies con- 
siderably, it is unlikely that they will all be able to compete with conventional technology in the short-term. Policy inventions are thus required, and the associated literature on how to achieve this is rich. As an example, Sandén and Azar (2005) argue that short-term climate goals can be met by economic policies, but for longer-term reductions, more complex technology policies are needed. IPCC (2007) provides an overview of national and international policies and assesses their applicability to various institutional contexts.

In addition to technological innovation, the economic literature also provides theoretical framing for technology transfer (Mukherjee, 2007), but the policy research literature on this is more extensive. For example, considering technology transfer in the context of India, Ockwell and Watson (2007) allude to both vertical and horizontal technology transfer in the context of a development continuum. Their literature review draws on Freeman (1992) and Gallagher (2006) to classify technological change into four types: incremental, radical innovation, changes of technological systems, and changes in techno-economic paradigm. They highlight six themes not dissimilar to the existing UNFCCC technology framework, including supplier/recipient firm strategies, absorptive capacity, and intellectual property rights (IPRs).

An important typology of the technology issue is defined by amongst others IIASA (2007), and contains a) Hardware: manufactured objects (also referred to as 'artifacts'); b) Software: knowledge required to design, manufacture, and use technology hardware; and c) 'Orgware': institutional settings and rules for the generation of technological knowledge and for the use of technologies. The importance of the latter is often underestimated, particularly in developing countries where orgware is a major challenge (Outhred, 2008). Outhred also notes the importance of considering not just hardware, but the systems in which they are embedded (i.e. electricity generation and distribution systems, including markets and infrastructure). In addition, ensuring the requisite technological and systems change will require considerable project management skills. These skills, in addition to specific technical skills, will need to be transferred along with technology. As mentioned, it appears that orgware is perhaps the hardest challenge; this is not necessarily appreciated in policy development.

Innovation systems literature is relevant to consideration of low-carbon technology. A technological innovation system refers to socio-technical systems focused on the development, diffusion and use of a particular technology (in terms of knowledge, product or both) (Bergek et al., 2008). An innovation system consists of the actors, networks and institutions (in terms of rules and norms, not organisations) that contribute to the overall functioning of developing, utilizing and diffusing new products and processes (Carlsson, 1997). Technological innovation systems can be analysed on the international, national (Lundvall, 1992; OECD, 1997) or regional (Braczyk et al., 1998; Cooke et al., 1999; Fisher, 2001) level ${ }^{13}$. Importantly, innovation systems for different technologies usually look very different within the same country or region. Similarly, the innovation system for a certain technology may look different in different countries or regions. Thus, there is a need for technological as well as geographical differentiation when designing policies to stimulate technological innovation.

Since the 1990's, research regarding innovation related to sustainable development and environmentally sound technology, including low-carbon energy technology has increased enormously (e.g., Kemp, 1997; Rip and Kemp, 1998; Tukker and de Bruijn, 2002; de Bruijn and Tukker, 2002; Hall and Kerr, 2003; Magnusson et al., 2003; Jacobsson and Laubner, 2006; Grubb, 2007; von Malmborg, 2007; Hekkert and Negro, 2008). Drawing on evolutionary economics, socio-technical change and innovation can be modelled as an interactive process of variation (e.g. knowledge within single organizations or networks) and selection (e.g. social and institutional preferences) that leads to certain preferred technological trajectories or sociotechnical regimes (Dosi, 1982; Nelson and Winter, 1982; Dosi et al., 2000). In addition, innova-

\footnotetext{
${ }^{13}$ More detailed studies of the innovation process include those by Nelson and Winter (1982), Dosi (1982) and Hughes (1983).
} 
tion is closely linked to organizational learning (and unlearning) and the exploration or exploitation of knowledge in a company or a larger socio-technical system (Henderson and Clark, 1990; Tidd et al., 1997; Sadler-Smith and Badger, 1998).

Most of the literature discussing innovation system failure tends to focus on perceived weaknesses in the structural composition of a system. For example, all the four types of system failures identified in a recent synthesis and re-categorization of previous system failure literature (Klein-Volthuis et al., 2005) are related to structural components: infrastructural failures (related to actors and artifacts), institutional failures (related to institutions), interaction failures (related to networks) and capabilities failures (related to actors). It has been argued that this leads to ineffective policies (Bergek et al, 2008). In order to be able to identify the central policy issues in a specific innovation system, Bergek et al. (2008) as well as Hekkert and Negro (2008) have argued that a structural focus needs to be complemented with a focus on key processes functions that have direct and immediate impact on the development, diffusion and use of technologies.

The 'radicalness' of innovations depends on the degree of learning and behavioural adjustments among actors. A socio-technological transition (i.e. regime or paradigm shift) implies changes of the technology as well as the system in which it is produced and used, and these take place in a process of co-evolution and mutual adaptation. In contrast to system innovations, which require exploration of new knowledge and a creative destruction of old knowledge, incremental innovations like optimisation and re-design are associated mainly with exploitation of existing knowledge and no large scale unlearning takes place.

From the literatures on innovation, (evolutionary) economics, and sociology, it can be concluded that different kinds of innovations require different approaches in terms of policies and measures. There are several functions that must be fulfilled for a technological innovation system to successfully deliver. These include, inter alia: development and diffusion of scientific, technological, production, market, logistics and design knowledge; influence on the direction of actors' search for entry and different options within an innovation system; entrepreneurial experimentation; market formation; 'legitimation'; resource mobilisation (in terms of human capital, financial capital and complementary assets); and development of positive external economies (Bergek et al., 2008). It is in these processes where policy makers may need to intervene, not necessarily in the set-up of the structural components (i.e. actors, networks, institutions). The main benefit is that it allows the separation of structure from content and to formulate both policy goals and policy problems in functional terms. ${ }^{14}$ It is believed that such a functional approach to innovation systems may add value to the ongoing discussions under the UNFCCC on how to scale up investments in environmentally sound technologies for mitigation and adaptation, and thus discussions on the elaboration on an enhanced technology framework ${ }^{15}$.

\subsection{Models, tools and scenarios for technology}

There are a wide variety of analytical models being used to consider and inform climate change policy at national, regional, and global levels. The IPCC Fourth Assessment Report (IPCC, 2007) found that there are over 750 emissions scenarios in the literature, and all of them consider different portfolios of technologies. Such models help us "to identify the mix of early

14 For example, the lack of research institutes has often been identified as a major problem in the Swedish National Innovation System, without much empirical evidence that this structural characteristic influences innovation processes in any important way. By focusing on functions, we could be able to analyse how research institutes in other countries influence the innovation process, and then see if this type of influence is absent in the Swedish system or if the same type of influence is present through another type of actor.

15 It may be of value to integrate such analysis in technology needs assessments (TNAs), and in the preparation of plans and strategies of different countries as for how to implementing climate technologies. 
technology investments that will satisfy multiple social goals (national [energy] security ${ }^{16}$, environmental quality, equity, and a robust economy) - given conditions of deep uncertainty" (Laitner, 2006). Others help communication about technology: the simplicity of Pacala and Socolow's (2004) wedges approach has influenced recent thinking in the technology and climate interface. It is perhaps most powerful as a conceptual tool for graphically illustrating to a wide audience the scale of the challenge and the importance of a diversity of technologies to tackle climate change.

The outputs, as well as the temporal and spatial scope, sophistication, language, assumptions, system boundaries, and theoretical frameworks of these analytical tools vary dramatically across the different models. They generally require assumptions about the technical status, potential scale and rate of deployment, costs and future costs and social acceptability, within an assumed framework for decision making - typically cost minimisation. Thus, the results of these analyses require considerable filtration and translation in order to appropriately inform design and implementation of government policy.

The principal forums for comparing energy/climate/Integrated Assessment Modelling (IAM) models include: the Energy Modelling Forum (EMF) (Weyant, 2004), the Innovation Modelling Comparison Project (IMCP) (Edenhofer, 2007), the US Climate Change Science Programme (CCSP) (Clarke, 2006), and IPCC (2007) ${ }^{17}$. Still, the outputs of these efforts require significant translation in order to inform negotiations, and are often not entirely useful in considering 'software' or 'orgware' dimensions.

Marginal abatement cost curves on various levels of aggregation can be used as an instrument to estimate abatement costs and potential on the national and global level (den Elzen, 2007; EC, 2003; EC, 1999; Ellerman, 1998). Global technology-focused marginal abatement cost curves, such as those prepared by Vattenfall/McKinsey (2007) (Figure 2.1). Bakker et al. (2007) and IEA (2008a) are useful in considering technology priorities and relative costs ${ }^{18}$. However one global curve is not sufficient to inform a comprehensive approach. Energy efficiency (or aspects of it) often appears with negative marginal abatement costs in these exercises, illustrating that the complex nature of technology development is not solely related to economic costs. Indeed, they would seem to highlight that price signals such as those provided by emissions trading are unlikely to drive optimal levels of our key technology response for significant emissions reductions (MacGill, 2008). Vattenfall/McKinsey (2007) did include detailed analysis of specific sector ('deep dives'). The building sector deep dive (residential and commercial) details many of the energy efficiency actions that comprise the negative marginal abatement cost potential of the global curve. The IPCC (2007) reflects the tendency to start with the less expensive mitigation options, “...the mitigation response...would shift over time from initially focusing on energy efficiency reductions in the beginning of the 21st century to more carbon intensity reduction in the latter half of the century.”

${ }^{16}$ Kuik (2005); Hoff (2007), and WRI (2007) all consider the relationship between energy security and climate change goals and structures. Although the framework proposed in this paper does not make explicit links to energy security, such connections could be formalised when designing and reporting on metrics of success.

17 Other results showing various technology portfolios include: Nakicenovic (2000), Uyterlinde (2004), Weyant (2004), Riahl (2006), van Vuuren (2006), Boeters (2007), Bruckner (2007), Das (2007), Höhne (2007), IEA (2007), Strachan (2007).

18 There is an enormous literature on the overall costs of climate change on society. Tol (2007) provides a statistical analysis of over 200 studies and concludes, "The median of the Fisher-Tippett kernel density for peer-reviewed estimates with a $3 \%$ pure rate of time preference and without equity weights, is US\$20/tC...[however] the uncertainty is so large that a considerable risk premium is warranted." 


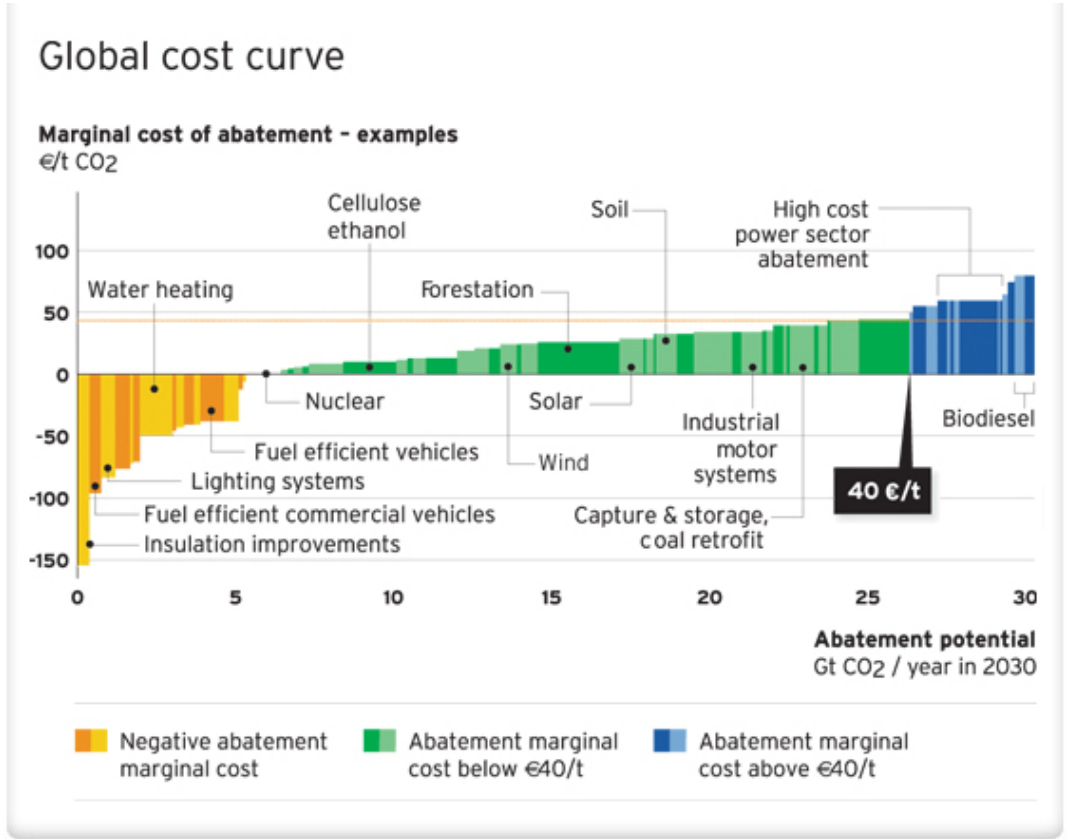

Figure 2.1 Vatenfall/McKinsey MACC in 2030

Source: Vatenfall, 2007.

In considering how these curves should influence policy Fisher (2005) reminds us that, “... costs of stabilization crucially depend on the choice of the baseline, related technological change and resulting baseline emissions; stabilization target and level; and the portfolio of technologies considered.”

Van Vuuren (2007) also provides a detailed technology analysis to meet the dramatic shift required to reach a 450 ppmv stabilisation target over a longer time horizon (to 2100). His work has formed the basis of the 'lower range' of stabilisation targets, which rarely go below 450 ppmv (IPCC, 2007). Obersteiner (2002) gives a detailed account of the feasibility of 'negative' $\mathrm{CO}_{2}$ energy production from bioenergy with CCS. This is the type of technology required to meet some of the lower scenarios (Van Vuuren, 2007), and shows that meeting stabilisation at this level will require radically new thinking. William Nordhaus (2007) has used his DICE model to consider a number of post-2012 policy options ranging from no action to moving into geo-engineering (Shrag, 2007). The IEA ETP 2008 work (IEA, 2008a) shows interesting detail on technology's contribution to emissions reduction targets to 2050, with energy efficiency making up over a third (Figure 2.2) ${ }^{19}$. The total additional investment required to meet the 'Blue Map' scenario ( $50 \%$ reductions in $\mathrm{CO}_{2}$ by 2050) is estimated at USD45 trillion ${ }^{20}$. The issue of timing, or capital stock turnover, is essential in considering the role of technology; creating an impetus for short-term action. This is considered in detail in the IEA's WEO (2007).

19 IEA (2008) shows EE making up around 54\% of the total mitigation required in a 450 ppmv case.

20 But has significant savings, “...total undiscounted fuel cost savings for coal, oil and gas are greater than the additional investment required” (IEA, 2008a). 


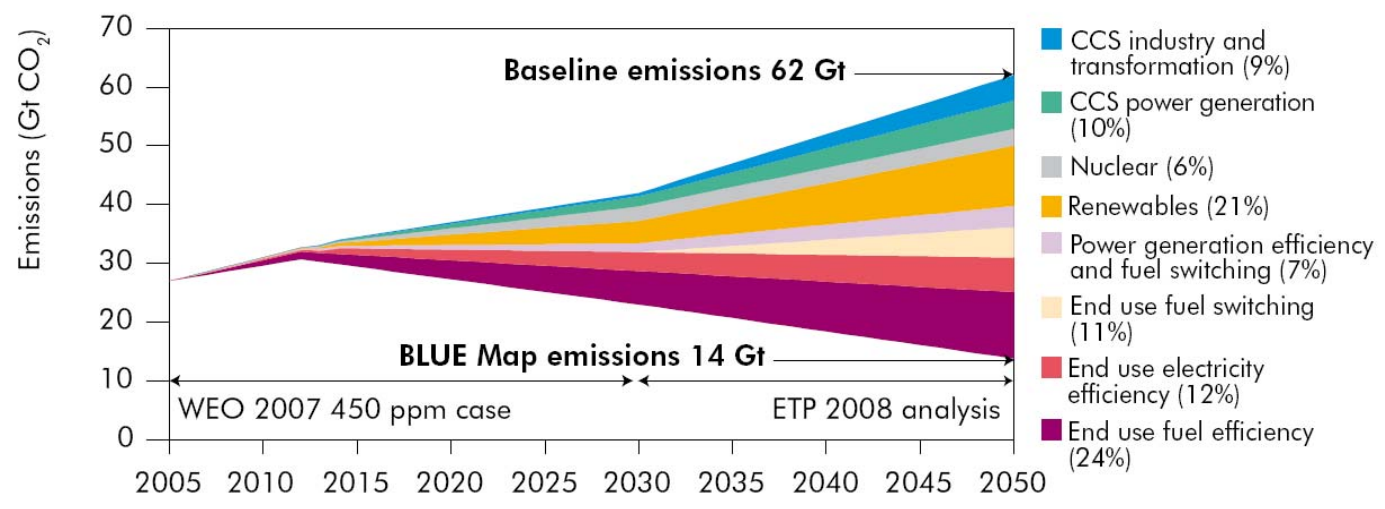

Figure 2.2 IEA Technology portfolio for the Blue Map scenario

Source: IEA, 2008a.

Each of the technologies considered (seventeen in all) in the IEA ETP (2008a) has an associated roadmap outlining a development and implementation pathway. Likewise, the Japanese Cool Earth (2008) programme identified twenty-one technology pathways, and the EC has considered 'technology maps' for 14 technologies (EC, 2007d). The IEA pathways consider overall target deployment targets to meet the scenarios, but what may be most useful within the UNFCCC process are the recommendation related to international collaboration regarding legal and regulatory frameworks, policy instruments, efforts to overcome social barriers, the stage of technological maturity, and international organisations that might be utilised.

The IEA ETP (2008a) also categorised various low-carbon technologies (Figure 2.3 shows those related to the power-sector) by potential as well as stage of development. This typology is useful in bridging resource abatement analysis to public policy.

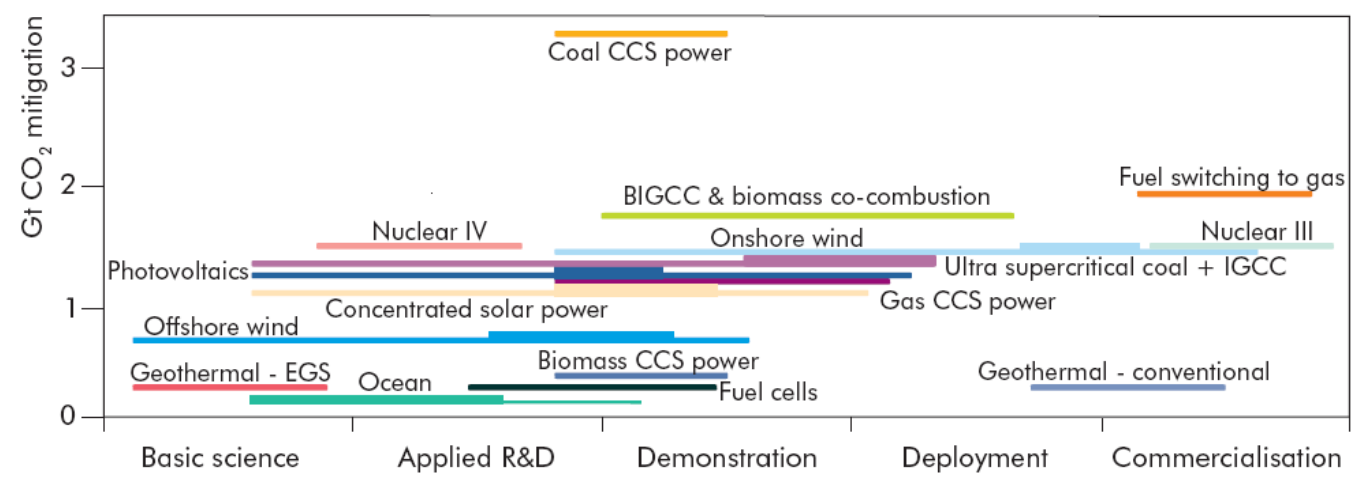

Figure 2.3 Categorisation of power sector technologies and their mitigation potential Source: IEA, 2008.

The developing country Parties that submitted TNAs identified technologies in the energy sector required to support mitigation (UNFCCC, 2006b). As an example, in the EE technologies (this was also done for RE technologies) the categories are indicated along with the regions that identified them as crucial (Figure 2.4). 


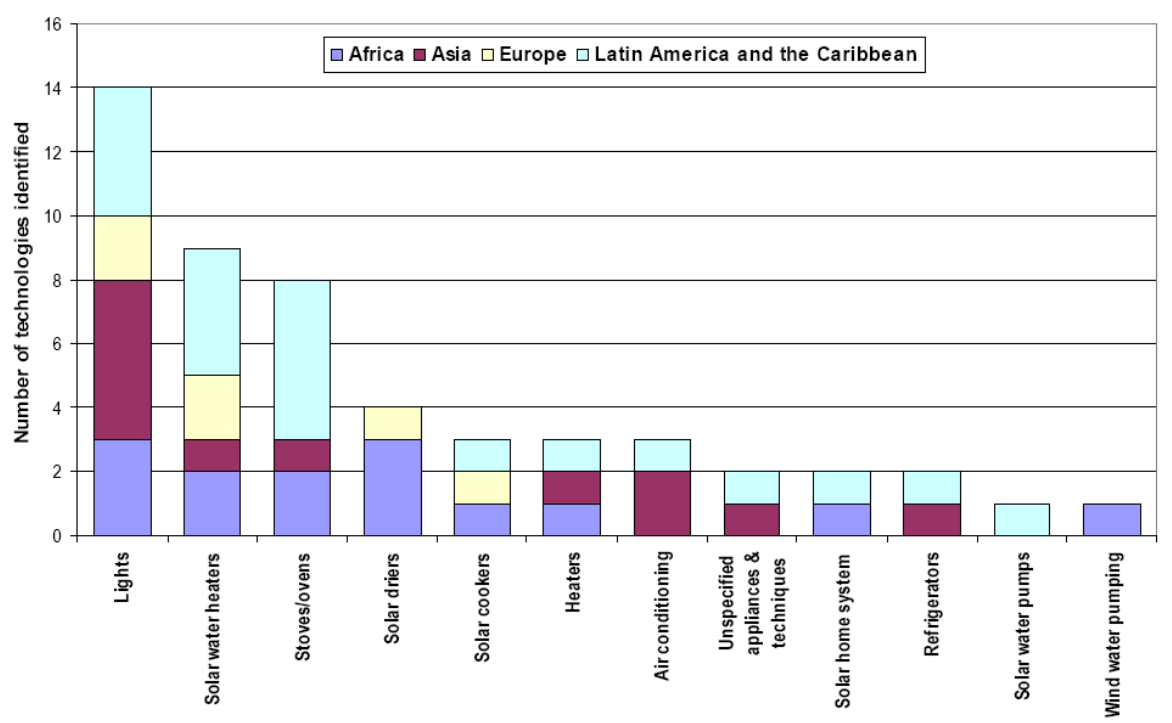

Figure 2.4 EE technologies needs in buildings and residential sectors Source: UNFCCC, 2006b.

Obersteiner (2002), noting the vast uncertainties in technology investment and deployment, utilises real-options theory to consider technological possibilities, as do Yang and Blyth (2007). This type of probabilistic approach (see also Bazilian, 2008) is essential in this area given vast uncertainty. Another approach for managing uncertainties related to an effective technology response to climate change is taken in the WWF Vision 2050 study (WWF, 2008). This study addresses a relatively narrow question of the technical feasibility of meeting growing global energy demand using sustainable energy technologies that will protect the global climate. The model doesn't assume technology costs or a carbon price - the costs of dangerous climate change are assumed to far exceed the costs of avoiding it. Instead, it focuses on key questions of the physical resources, the capacity of the technologies themselves and the rate of industrial transitions. Uncertainties are explicitly modelled. The results suggest that there is a reasonable chance of success, however, physical and engineering constraints, regardless of a carbon price or other policy measures, limit the rate at which emissions can be bought down and that some overshoot of emissions may be inevitable.

There are a rich array of theories, tools and models to study technology and investments, and their relation to climate change mitigation. However, specifically addressing how technology can be embedded and enabled in the international climate regime remains largely unanswered by the literature reviewed, and will be the subject of the following sections. 


\section{Technology in the climate negotiations}

This section outlines the existing basis for a technology framework or mechanism under the UNFCCC and considers what role the treatment of technology may take in a future climate agreement. It argues that approaches to technology need to be differentiated on a national and regional basis.

\subsection{Technology in the UNFCCC context}

Technology is embedded in several articles of the UNFCCC ${ }^{21}$, the most important of which are Articles 4.1c, 4.5 and 4.7. Article 4.1c calls on all Parties to the Convention, "to promote and cooperate in the development, application and diffusion, including transfer, of technologies, practices and processes that control, reduce or prevent anthropogenic emissions of greenhouse gases". Article 4.5 calls on developed country Parties to, "take all practicable steps to promote, facilitate and finance, as appropriate, the transfer of, or access to, environmentally sound technologies and know-how to other Parties, particularly developing country Parties, to enable them to implement the provisions of the Convention.” This requirement for technology transfer - in effect technology support by developed countries to developing countries - is echoed in Article 4.7, which states that, "the extent to which developing country Parties will effectively implement their commitments under the Convention will depend on the effective implementation by developed country Parties of their commitments under the Convention related to financial resources and transfer of technology".

The issue of 'development and transfer of technology' has been a permanent item on the agenda at all COPs since the ratification of the Convention, and decisions have been made to further elaborate provisions related to technology with particular focus on enhancing the implementation of the technology specific articles of the Convention. Among these decisions, 4/CP.7, adopted as part of the Marrakesh Accords in 2001, is of particular importance. This decision includes agreement by Parties to work together on a set of technology transfer activities, grouped under what was labelled, “.... framework for meaningful and effective actions to enhance the implementation of Article 4.5 of the Convention.” This framework, contained in the annex to decision 4/CP.7, has five main themes:

1. Technology needs and needs assessments;

2. Technology information;

3. Enabling environments;

4. Capacity building;

5. Mechanisms for technology transfer.

The framework mainly provides a list of actions to serve as guidelines for governments and other actors. With regard to structures under the UNFCCC, the technology framework identifies two parts. First, the element of technology information includes a web-based technology transfer clearing house (TT:Clear), which includes technology-related material and programme descriptions of all five themes of the framework. Secondly, the element of technology mechanisms

\footnotetext{
21 The background to the technology aspects of the UNFCCC process are well documented in Tanunchaiwatana (2007). Beginning with Articles 4.5 and 4.7 of the UNFCCC, the key COP decisions on this issue are identified including, 4/CP.7 and 6/CP.10. The other convention provisions and decisions normally recalled in this context are: Article 4, paragraphs 1, 3, 5, 7, 8 and 9, Article 9, paragraph 2(c), Article 11, paragraphs 1 and 5, and Article 12, paragraphs 3 and 4, and decisions 4/CP.7, 6/CP.10, 6/CP.11 and 3/CP.12, In addition Chapter 34 of Agenda 21 on the transfer of environmentally sound technologies is often cited in UNFCCC text.
} 
includes the Expert Group on Technology Transfer (EGTT), which is supported by the UNFCCC secretariat and reports to both permanent subsidiary bodies under the UNFCCC. ${ }^{22}$

At COP 13 in Bali, 2007, the technology transfer framework was reinforced and enhanced with an additional set of actions to be undertaken by governments and intergovernmental organisations (3/CP.13). In addition, the EGTT was reinforced with a new five year mandate (20082012). The primary function of the EGTT is to analyse and identify ways to facilitate and advance the development and transfer of technology activities related to the UNFCCC, including those identified in the technology transfer framework, and to make recommendations for consideration, as appropriate, to the SBSTA and the SBI to inform subsequent relevant decisions by the COP.

At COP 13, Parties also agreed upon the so-called Bali Action Plan (decision 1/CP.13), which sets out (para.1), "a comprehensive process to enable ...long-term cooperative action, now, up to and beyond 2012, in order to ....adopt a decision at its fifteenth session.” The Bali Action Plan identified technology, or rather "enhanced action on technology development and transfer", as one of four building blocks (para.1d) of a future international climate change regime. Together with enhanced action on the provision of financial resources and investment (para.1e), technology is a supporting pillar to the building blocks of climate change mitigation (para.1a) and adaptation (para.1b), and is explicitly referred to in relation to the building blocks of finance and mitigation.

It is not clear how the building blocks will be translated into a Copenhagen Agreement at COP 15, but with regard to technology Parties will consider several issues including (para.1d): (i) mechanisms to accelerate deployment, diffusion and transfer of affordable environmentally sound technologies, including mechanisms for removal of barriers and provision of financial and other incentives; (ii) cooperation on research and development of current, new and innovative technology; (iii) mechanisms and tools for technology cooperation in specific sectors, including sectoral approaches; and (iv) measuring, reporting and verification of technological (as well as financial and capacity-building) support for nationally appropriate mitigation actions by developing country Parties.

\subsection{Technology as a design feature of a 'deal'}

There are numerous proposals for post-2012 UNFCCC agreements. The bulk of these focus on the nature of mitigation targets and how they should be derived. ${ }^{23}$ Analysis of these proposals can be found in: Benedick (2001), Aldy (2003), Den Elzen (2003), Pew Center (2004), EC (2005), Muller (2005), Potsdam (2007), and Höhne (2003, 2005, 2006, 2007, and 2008). There is also a growing literature on a specific technology agreement, or how best to integrate technology into a wider post-2012 UNFCCC agreement (G8, 2008; Blair, 2008; Stern, 2008). EC (2005b) highlights four elements of a future agreement and explicitly includes the need for agreement on technology in addition to reduction targets. Likewise, Pew Center (2005) describes elements of 'parallel' efforts required which includes technology cooperation. IEA (2008) describes a 'hybrid' approach of sectoral agreements, national policies and measures, and cap and trade. The literature also highlights the potential for 'technology push' and 'market pull' measures to be superior when used together rather than separately (Norberg-Bohm, 2000). Some of the early influential organisations within the UNFCCC were technology focussed - for

22 From 2001 to 2007, the EGTT reported only to the Subsidiary Body for Scientific and Technological Advice (SBSTA), but due to revised terms of reference for the EGTT, decided at COP 13 in Bali 2007, the expert group is now also reporting to the Subsidiary Body for Implementation (SBI).

23 There are also an enormous number of new entities and NGOs emerging as forums for the discussion and elaboration of climate change policy, many of which are focused on technology. These include organisations like the Copenhagen Climate Council (2008), Climate Works (2008), and those organisations set up to support messages from Al Gore, Tony Blair (2008), and Bill Clinton. It is not yet clear how they will influence climate policy, or how their message will affect the broader public. 
example, the nuclear industry. However, it might be argued their influence diminished in the debate as the policy debate moved towards market-based measures such as emissions trading.

Agreement on aspects of technology may engender wider support for an overall package based on developed country targets ${ }^{24}$. Another feasible, yet less attractive, outcome is where a technology agreement might serve as the basis for the totality of the agreement in the case where negotiations on developed country targets and developing country actions are not concluded. To that effect, Sugiyama (2005) offers a useful note of caution, urging negotiators to, “...ensure that technology and development cooperation do not dilute political attention to climate change, and that the [carbon market] regime does not cripple technology and development cooperation by creating an adversarial negotiation atmosphere."

Most environmental policy, until recently had largely been based on technology-focussed command-and-control regulation (MacGill et al., 2006). The UNFCCC marks a deviation in moving from a 'means' to an 'ends' approach, or from a process to an outcome-based approach. Its focus on national emissions targets also emphasises the idea of market-based policy approaches for achieving them ${ }^{25}$. In essence this leaves market participants to resolve which technological and other changes are most efficiently able to deliver the required target. There have been increasing challenges to the validity of the strict interpretation of this approach, provoked mostly by US researchers, claiming that commercialisation of a number of promising technologies is needed (Hoffert et al., 2002), and that feasible technologies can reduce emissions substantially (Pacala and Socolow, 2004). Others have suggested that an agreement based on technology might provide better incentives for participation than an emission targets or even cap-and-trade based regime (Barrett, 2001). This type of focused agreement may appeal to specific Parties and thus be more 'transactable', but would likely lead to a more fragmented climate regime. There are enormous benefits in terms of efficacy, choice, negotiating resources, etc. in maintaining the holistic coherence of the UNFCCC. Any technology approach should thus be carefully integrated into a wider agreement. However, it is conceivable that an 'energy only' agreement (or a land-use one) for example, could be subsumed within the whole without losing the high-level emissions reductions target approach.

The ability to reciprocate, and the trust that reciprocity will be provided through concessions, is one of the defining characteristics of international cooperation (Goldstein, 1991; Welsh Larson, 1988) but is also used as a design feature of international treaties (Bagwell and Staiger, 1999). Keohane (1986) makes a distinction between 'specific' and 'diffuse' reciprocity. In cases of specific reciprocity, "partners exchange items of equivalent value in a strictly delimited sequence". The boundary between specific and diffuse reciprocity is not clearly delineated, but Keohane argues that agreement is more likely when reciprocity is less diffuse because the mutual value of the agreement is more obvious to the Parties.

There are reasons to view technology as an opportunity and a reciprocity-enhancing design feature of an international climate regime. In a technology agreement, the reciprocity lies in that by choosing to participate, countries have the possibility of accessing or supplying certain technologies. Under a technology-neutral cap and trade-based agreement, such benefits of participation may not always be clear and reciprocity is more diffuse. Whether the reciprocity of accessing or supplying technology will be valued by countries, however, depends on an assumption that countries have incomplete information about technologies, and that they will benefit from the agreement even if they do not emerge as the leading suppliers of a given new technology ${ }^{26}$.

\footnotetext{
24 Notionally, the psychologically 'upbeat' character of technology, which elicits associations with wealth, innovation and progress, compared to emission reductions, which framed in terms of economic constraints, might make a contribution to securing an agreement that is comprised of both elements.

25 Some market-based measures may also actually reduce technology innovation, at least in the early phases. This is illustrated in the EU ETS by Betz and Sato (2006).

26 Note that, contrary to most game-theoretic exercise (see e.g., Buchner and Carraro, 2005), in this unformalised game, incomplete information is used as an advantage for goal attainment.
} 
The incentive to participate in such an agreement thus stems from the possibility of accessing such information, and whether countries foresee receiving advantage from it. This advantage may arise from being a key supplier, from having a high value context for a technology, such as a favourable wind regime, or from rural electrification challenges.

The focus on technology has a number of other benefits, related to co-benefits, costpredictability and the 'psychology' of environmental targets. A technology-neutral emission reduction target does not provide information to those signing up to the target on what the impacts on energy security, air quality, sustainable development or costs would be. In this type of system, market participant's decisions would match wider societal objectives only to the extent that these are also priced into the decision making - an unrealistic expectation. By contrast, as an example, calculations of co-benefits and integrated cost-effectiveness of combined air quality and climate change measures based on emission reductions focus on the technological level (Cofala et al., 2004; van Vuuren et al., 2006, 2006b). The notion of sustainable development and energy security as side effects or co-benefits of climate policy needs to be carefully considered. Whether policies are designed with a focus on energy security, or on climate change (or on industrial development, etc.), will have a significant impact on the result. While not mutually exclusive, the two different foci do not necessarily guarantee a 'glorious' result (Bruckner, 2007). It depends quite specifically on the fuel, the technology, the natural endowments of a country, and on the political context in which it figures whether climate and energy security goals are compatible $^{27}$. Technology-focused policies, however, can help clarify what the benefits or drawbacks are, and provide better certainty regarding costs.

\subsection{Technology requires a differentiated approach}

Technologies can be categorised by their state of technical maturity, the nature of their associated energy service market (electricity, thermal, motive), their potential for mitigation, or supply or demand-side impacts. While public policy recognises the need to differentiate policy and regulatory approaches based on these categorisations, within the UNFCCC it will be useful to acknowledge the dramatically different national and regional capabilities, markets, and resource-bases that exist. There has been enormous growth in the production and use of many clean energy technologies over the last decade. This growth has been concentrated in a very few countries, however. Simple assumptions about the deployment of these technologies in developed and developing countries are no longer appropriate (REN21, 2008). As Figure 3.1 shows, the Chinese and Indian markets rank along with the largest of the OECD markets and constitute the bulk of the developing country RE market. Additionally, NEF (2007) data by country indicates India and China as significant players, challenging the notion of technology transfer as only a North/South paradigm.

${ }^{27}$ For example, there are obvious synergies between renewable energy and energy efficiency for both climate and energy security objectives. Conversely, substitution of coal-fired generation by gas-fired generation may have adverse energy security outcomes even while offering low-cost emissions reductions. 


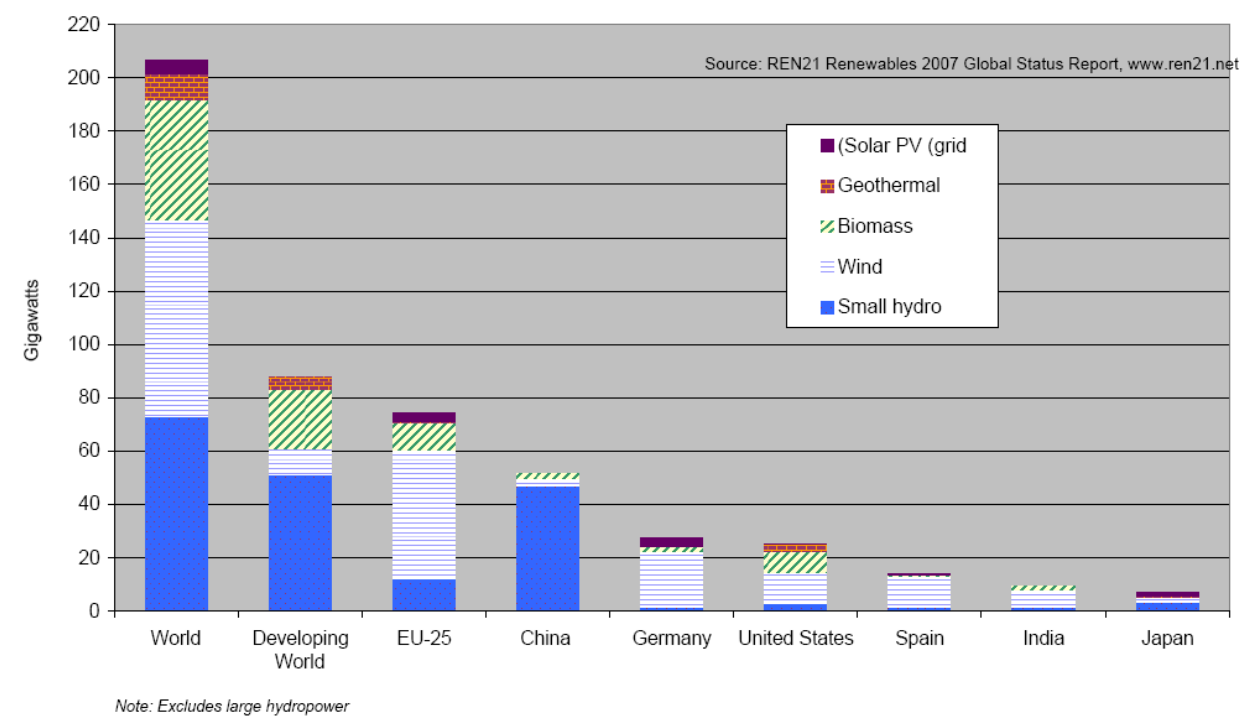

Figure 3.1 Renewable energy penetration by technology and region Source: REN21, 2008.

It is clear that technology deployment will require different approaches linked to specific national and regional circumstances, as well as stage of technology development. The IEA (2005) notes, “...developing countries can offer opportunities to deploy climate-friendly technologies more cheaply than in OECD countries. OECD technology deployment investments could therefore be enhanced if undertaken in these countries.” To make this case for differentiation of policies and support required, the World Bank (2008) shows the vast discrepancies between various countries both within the same income brackets and between income classes in penetration of new technologies (Figure 3.2).

The Clean Development Mechanism (CDM) market offers empirical evidence for the need to differentiate. The vast bulk of projects have occurred in a very few countries, with large parts of Africa receiving very little investment, and in a limited number of sectors; particularly the transport and household sectors are underrepresented (UNEP Risø, 2008). More generally, the experience of the CDM to date highlights that many participants in environmental markets are primarily driven by only those policy objectives that are monetised. The CDM has joined sustainable development and emissions reduction objectives, however, it is the latter objective that is monetised for project developers - the market is naturally driven towards large-scale, low-cost abatement rather than those offering high sustainable development outcomes (MacGill et al, 2006).It is clear that the market conditions in the developing world are far from homogenous, leading to very heterogeneous results for low-carbon technology implementation. This issue was addressed by the UNFCCC at COP13 (Nairobi) to some extent, but recent numbers do not yet show a detectable change. 
Penetration of newer innovations (2000-03)

Index

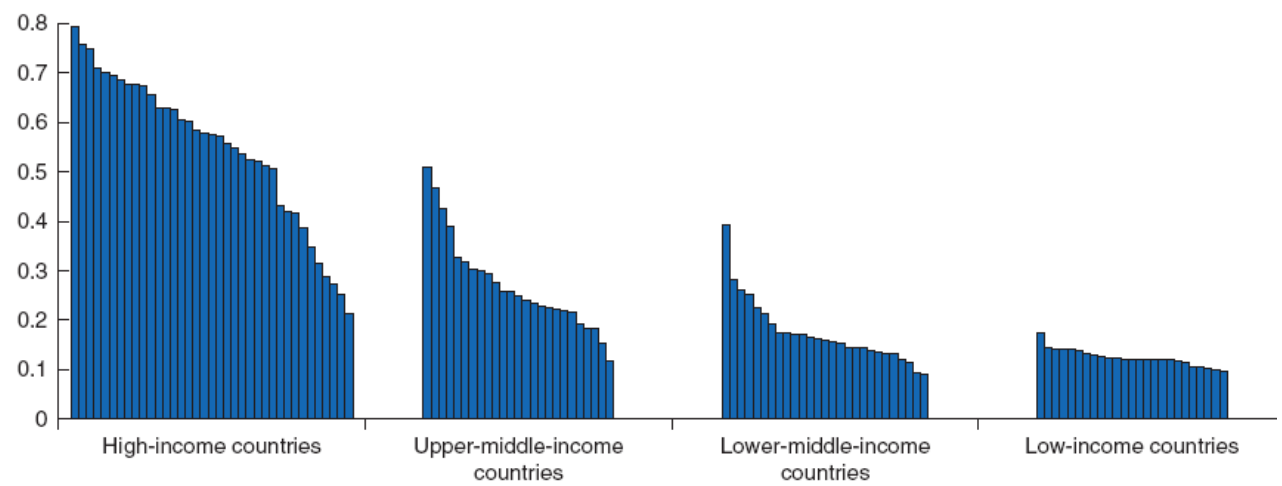

Figure 3.2 Penetration of new technologies by income level

Note: Each bar represents a single technology, and the height of the bar shows its penetration level in the country type.

Source: WB, 2008.

The rest of the paper assumes the need for a differentiated and country (or at least regional) focus of specific elements in an enhanced technology framework. 


\section{Priority elements for an enhanced treatment of technology}

This section focuses on six areas (enabling environments, intellectual property rights, trade, technology agreements, SD-PAMS, and finance) where distinct programmes and structures could be implemented by the UNFCCC or its Parties to advance technology and enhance technology transfer ${ }^{28}$. These areas could be seen as elements of an enhanced technology framework, forming what is essentially an implementation phase (post-2012) when compared to the current situation, which could be described as a pilot or investigative phase regarding transfer of environmentally sound technologies under which needed innovation and learning could occur. As such, derivatives of these areas can also serve as criteria for an enhanced technology framework, which will be discussed in Chapter 5 .

Jaffe et al. (2001) conclude (on the area of stimulating the development and deployment of lowcarbon technologies) that, "Much of this debate has been explicitly or implicitly ideological or political. More useful would be detailed examinations regarding the kinds of policies and the kinds of private-sector institutions that are most likely to generate innovative, low-cost solutions to environmental problems." It is proposed that an enhanced technology framework should serve as such a necessary 'intermediary' for such solutions to be designed and implemented.

\subsection{Enabling environments}

The transfer of technology integrates, "human beings, know-how, physical objects and techniques" (Karani, 2001). Technology transfer cannot be hardware transfer alone; it must necessarily involves building human and institutional capacity to handle the technology and the raising of awareness among users and other stakeholders, including civil society (Reddy, 1991; Lall, 1992; IPCC, 2000; Forsyth, 2005, 2007). The term 'enabling environments' embodies these fundamental pillars of technology development, deployment and transfer. In the UNFCCC context, the term generally refers to appropriate conditions for the uptake and deployment of low-carbon technologies. This involves policy, market and regulatory conditions as well as people and institutions. The process of strengthening enabling environments is inherently tied to economic development and basic issues of governance facing developing countries ${ }^{29}$.

Figure 4.1 schematically depicts some of the conditions impacting the enabling environment. It illustrates the factors that direct policymaking can address. This practical focus, however, does not explicitly reflect many of the underlying factors such as, "tacit knowledge, the internal organisation of the firm, interactions via inter-firm linkages, supply chains and networks, past learning efforts, investments in human capital and 'learning by doing', market structure and competitive pressure, government interventions to correct the failure of markets for knowledge (education, R\&D training), government led institutional arrangements to facilitate innovation (R\&D labs, technology intermediaries), and finally access to finance” (Bell and Pavitt, 1993). The UNFCCC defines (through Article 4.5 and 4/CP.7) enabling environments as, "fair trade policies, removal of technical, legal and administrative barriers to technology transfer, sound economic policy, regulatory frameworks and transparency, all of which create an environment conducive to private and public sector technology transfer."

\footnotetext{
${ }^{28}$ Useful lessons can be drawn from successes achieved under other Multilateral Environmental Agreements (notably the Montreal Protocol's Multilateral Fund), and successful structures and mechanisms proven elsewhere (e.g. CGIAR) might be usefully adapted to fit the climate change challenge.

29 The term innovation is sometimes used in this area to encompass this wide area (as in the literature review), although it tends to be focused towards R\&D and demonstration, rather than on commercial or market deployment. The Ghana (2008) proposal makes this link explicit.
} 


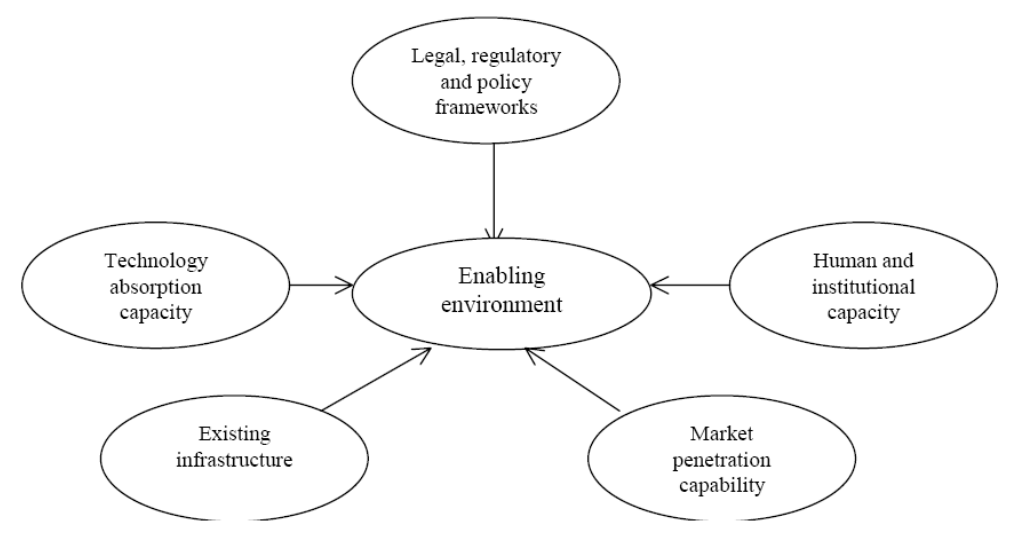

Figure 4.1 Enabling environments schematic Source: UNFCCC, 2003.

As highlighted in the theoretical literature, governance, institutions and associated human capacity are critical to wider deployment of climate change technologies, the rate of which is likely to be determined by the absorptive capacity of a country, region or sector. Hence, this paper treats efforts to build capacity as a critical input to the creation of enabling environments. In many developing countries, and the LDCs in particular, this is likely to be the area on which to focus attention. These issues are, however, difficult to address in the confines of the UNFCCC negotiations because of the very broad nature of institutional requirements, sovereignty sensitivities and because they are closely linked with all other areas of public policy. These sensitivities are particularly pronounced in areas related to legal, regulatory and policy frameworks. However, indicators of development (see Section 5.3) may provide (at a macro level) guidance on where instruments can be most usefully employed to strengthen enabling environments.

There is a large array of ongoing activities in the areas of human and institutional capacity building, both within and outside of the current technology framework of the UNFCCC. As an example $^{30}$, UNIDO (2008) has programmes like: Network of University Chairs on Innovation, Support for Development of Technology Parks (PLATECH), Industrial Subcontracting and Partnership eXchange (SPX) Programme, Investment and Technology Promotion Offices (ITPO), Business Environment and Policy Support Unit that could all be augmented to focus on low-carbon energy technologies development and diffusion. EC (2007e) provides a useful 'capacity map' focusing on EU R\&D.

Within the UNFCCC, the issue of capacity building is embedded in Article 9 of the Convention and Article 10(e) of the Kyoto Protocol. Decisions 2/CP.7 and 3/CP.7 are the frameworks for capacity building agreed in Marrakech. UNFCCC (2007c) shows hundreds of activities and needs related to capacity building in developing countries, mostly implemented by the Global Environment Facility (GEF). The COP has given the GEF direction to help support inter alia capacity building (2/CP.4). Through the TNA process, countries identified a number of activities that could now be considered for further funding either through the GEF or other programmes developed as part of the enhanced framework. They include efforts to: train key personnel in technology issues, train installers, create technology transfer centres, develop courses and research initiatives, establish national and regional technology networks, and move towards technology market assessments (GEF, 2008). These activities, which were identified by countries (UNFCCC, 2006b) with funding ranging from roughly USD100,000-300,000, could be increased by an order of magnitude in moving from scoping to implementation. Related to technical information, the UNFCCC's TT:Clear initiative supports a network of information centres, and a technology and project database.

30 The UN CSD Partnership web page lists upwards of ten partnerships specifically named as capacity building partnerships UNCSD (2008). See also UNDP (2005, 2008). 
Outside of the Climate Convention, UNEP has partnered with UNIDO (2008) on 24 National Cleaner Production Centres in the developing world. UNDP's country offices, regional centres, and sub-regional resource facilities are important 'infrastructure' that can be augmented for lowcarbon technology programmes. There are hundreds of resources on capacity building (e.g. Fukuda (2001), UNDP (2005)), including a capacity resource library (UNDP, 2008). Fukuda (2001) and Lopes (2003) report on a three year UNDP initiative considering aspects of capacity building and technical cooperation. The UNFCCC National Focal Points (NFP) and initiatives like the National Communications Support Programme (funded by: GEF, managed by: UNDP and UNEP) could also both be augmented significantly to support technology development and deployment.

There are also other ongoing initiatives for enabling environments. The World Bank and UNDP's Energy Sector Management Programme (ESMAP, 2008) provides energy assessments, advisory services, focused studies, strategic advice and pre-investment advice with a focus on small and medium-sized enterprises (SMEs) and EE. It supports a network called the Energy Efficiency Thematic Group, and has implemented many programmes to support the deployment of renewable energy technologies in LDCs. The USA's National Renewable Energy Laboratory (NREL, 2008) provides a number of services in the area of technology transfer, such as technology partnerships and Cooperative Research and Development Agreements. Such programmes which have been effective in developed countries could be translated to developing countries. Along these lines, U.K.'s Carbon Trust (2008) proposes a series of innovation centres in a number of countries. In this context the term innovation is meant as nearly every stage from applied R\&D through deployment and energy policy. The breadth of the tasks and the focus would need to build on existing institutions in developing countries, and be carefully designed for national circumstance.

There is significant technical capacity within many developing countries that can be harnessed to this purpose. It is also useful to explore opportunities for 'South-South' collaborations to facilitate an exchange of innovative experiences with clean technology deployment and enabling environments across developing countries. The model of the International Energy Initiative, a "Southern-conceived, Southern-led and Southern-located South-South-North partnership" is an interesting example to consider in this context (IEI, 1988). The provision of enabling environments is perhaps the most cost-effective intervention that can be made under the UNFCCC. It is one where the need for public sector interventions is clear. These interventions would also have significant tertiary benefits and synergies with other developmental goals.

\subsection{Intellectual Property Rights}

There is increased attention to the effects of trade policy and Intellectual Property Rights (IPRs) on the development and transfer of low-carbon technologies. Recent interventions in various UNFCCC forums by countries such as India (2008) and Brazil (2008), for example, illustrate non-Annex 1 Party concerns regarding the potential barriers that overly protective IPR regimes could pose to the transfer of climate friendly technologies ${ }^{31}$. The basic concern is that restrictive IPRs will stifle innovation in developing countries, raise the costs of knowledge acquisition and learning, and impede climate change technology transfer.

\footnotetext{
31 Drawing on past experience with IPRs in the pharmaceutical sector, some have proposed an express statement along the lines of the Doha Declaration on the TRIPS Agreement and Public Health for the climate change/clean energy context to ensure that IPRs do not stand in the way of efforts to deploy clean technologies in developing countries (Brazil, 2008). Other proposals include the establishment under any post-2012 agreement of a multilateral funding mechanism that would be used to acquire ESTs (China, 2008), including via the acquisition of licenses for climate-friendly technologies that would then be made available at low cost to developing countries (Brazil, 2008).
} 
Not surprisingly, some of the Annex 1 Parties, and key stakeholders from the business community, are resistant to such proposals. The United States (2008), for example, has argued that strong IPR protections, such as those in the WTO TRIPS Agreement, are necessary (but not sufficient) conditions to facilitate the transfer of clean technology. Without strong IPR protections, the argument goes, there will be little incentive on the part of the private sector to make clean technology available to developing countries (Maskus, 2004). Rather than focus on IPR issues, attention should instead be given to other barriers impeding technology transfer, including existing tariff- and non-tariff barriers that retard investment in key developing country markets (USTR, 2007).

To date, evidence regarding the role of IPRs in the climate change technology transfer area is very limited and provides an insufficient basis on which to conclude that IPRs currently pose a significant barrier to the transfer of climate-friendly technologies (e.g., Mytelka, 2007; Barton, 2007; Lewis, 2007) ${ }^{32}$. In a recent study of three renewable energy sectors (PV, Wind, and Biofuels), for example, Barton (2007) concludes that intellectual property issues in these industries are not analogous to those in the pharmaceutical industry, where a specific drug may not have any substitutes, thereby bestowing upon the patent holder a strong market position and the ability to charge prices well above production $\operatorname{costs}^{33}$.

The literature and analysis remain nascent, however. ICTSD supports this conclusion, and notes, “.... unique conclusion on the relationship between IP and the transfer of climate-related technologies is far from feasible at the moment. . . . [I]t is clear that further research and analysis will be critical to achieve any effective solutions (Mytelka, 2007).” Empirical evidence on which to base policy design is lacking on many other aspects of technology transfer as well (Ockwell, 2007).

It is also important to recognise that the future may be quite different from the past with respect to the role of IPRs in the clean technology sector. Patenting of clean technologies continues to grow (Miller et al., 2008). Given the long lead times involved in clean technology development, the large sums required for commercial scale deployment, and the preference among venture capital investors for strong proprietary positions, the importance of IPRs in the sector will likely increase ${ }^{34}$.

In its pre-Bali resolution of November 2007, the European Parliament recommended a study of possible amendments to the TRIPS agreement to allow for compulsory licensing of "environmentally necessary technologies" (EP, 2008). It is important to recall that the TRIPS Agreement (Article 31) already allows for compulsory licensing in certain circumstances. The recent ICTSD report however, provides a note of caution on expanding compulsory licensing beyond the existing provisions in the TRIPS Agreement, pointing to the difficulties and political costs of opening up the TRIPS agreement for modification (Mytelka, 2007). Likewise, Wilson (2008) argues that "[c]ompulsory licensing will stop the $\left[\mathrm{CO}_{2}\right.$ mitigation] industry [from] reaching ma-

32 Likewise, in a detailed study of wind development in China and India, Lewis (2007) analyzes the growth of two dominant firms in these countries, emphasizing that, "[i]n both India and China, leading firms were successful in using licensing as a mode of technology transfer in the wind turbine industry.” Lewis (2007) concludes that "[t]his is particularly true for technology transferred from developed to developing countries, where a similar technology potentially could be manufactured in a developing country with less expensive labour and materials, resulting in an identical but cheaper turbine."

33 He also notes that many of the key technologies in these three renewable energy sectors have long been "off patent", that current patents relate mostly to improvements, that industry structure does not (yet) allow for cartel-like behaviour, and that competition in this area should bring cost reductions. He does caution that, "all countries should be alert to the risks of cartel-like behaviour" in these sectors in the future.

34 In some sectors (such as second-generation biofuels), it is possible that patents of broad scope could be granted over foundational technologies that could impede technology transfer. Likewise, product- and/or industry-specific GHG performance standards could bestow competitive advantage on firms holding patents over key technologies and may lead to restrictive licensing practices (Hutchison, 2006). 
turity." In his view, "the bigger threat to technology transfer is not strong IP regimes, but weak ones.”

Other, less controversial, suggestions that have been discussed in the literature include:

- Better definition of the role of the UNFCCC in addressing the relationship between IP and climate change technology transfer (Mytelka, 2007).

- Attention to the specific challenges associated with, IPR protections in rapidly developing countries as well as in the least developed countries (Barton, 2007; Ockwell, 2008).

- Further exploration of existing options under the current TRIPS agreement, with particular attention to the manner in which the so-called TRIPS flexibilities could be used (Mytelka, 2007).

- International collaboration on low-carbon technology development with IPRs for new technologies (Ockwell et al., 2007) ${ }^{35}$.

- Decisions by developed nations to forego the practice of preferential licensing of publiclyfunded technologies to national firms (Barton, 2007).

In terms of a post-2012 agreement, it seems unlikely that significant additional research will be available in time to inform detailed policy design prior to Copenhagen. Finding the proper balance between protection of IPRs and the promotion of technology transfer argues for a multipronged response that incorporates strong monitoring and early warning capabilities to detect possible abuses combined with back-stopping authority (and sufficient policy tools) in urgent cases $^{36}$. To that effect, the general conclusion of CIPR (2002) is worth recalling: "TRIPS has strengthened the global protection offered to suppliers of technology, but there is no international framework to ensure that the transfer of technology takes place within a competitive framework which minimizes . . . restrictive licensing practices." It is thus suggested that the near-term focus of a post-2012 regime should ensure that two goals are achieved: First, capabilities to detect and, where possible, remedy practices that restrict licensing, need to be developed and expanded, and secondly these should avoid imprecise approaches which would undermine the positive role that IPRs can play. Settling on the right division of labour in this context between the climate regime and the trade regime will be particularly important.

\subsection{Trade issues}

In contrast to the role of IPRs in the transfer of clean technology, the issue of trade barriers ${ }^{37}$ is relatively straightforward (Howse and van Bork 2006; Brewer 2007). Indeed, most commentators agree that reducing tariff and non-tariff barriers to clean technology should be prioritised over addressing IP issues (Barton 2007; EC, 2007b; Wilson 2008). Wilson (2008), for example, argues that the focus on patents as a barrier to technology transfer is a, "distraction from the real barriers that exist to technological diffusion in developing countries - tariffs and non-tariff barriers. In the top 15 greenhouse gas emitting developing nations, tariff barriers for $\mathrm{CO}_{2}$ mitigation technologies can be as high as 30 per cent. Non-tariff barriers can be as high as 160 per cent $^{38}$."

Echoing these analyses, the World Bank (2008a) concluded that removing tariff and non-tariff barriers to clean energy technologies could boost trade significantly and encourage greater in-

\footnotetext{
35 As an example of this issue in practise, NREL (2008) has a licensing agreement process in place for the technologies that they have developed

36 The political reality is that some developing countries that have been disadvantaged (or feel that they have been disadvantaged) by agreements governing international trade and intellectual property rights are looking to the UNFCCC process for support in the other forums.

37 This refers to import and export tariffs, and not issues of subsidies (considered further in Section 3.6).

38 Barton (2007) reaches similar conclusions, emphasizing the need to remove unnecessary barriers to trade in renewable energy technologies, though he also makes the important point that some of these barriers have been erected by developed countries, with the US tariff on Brazilian ethanol providing one of the more prominent examples.
} 
vestment in these technologies. Brewer (2007) likewise focuses on the trade aspects of technology transfer, calling for a more 'explicit and systematic' approach to linkages between goods and services to underpin technology transfer and urging an expansion of the negotiating agenda to include non-tariff barriers.

Not surprisingly, these issues have garnered increased attention in the WTO. Building on past interventions, in November 2007, the EU and the US issued a joint proposal at the WTO calling for trade liberalization in "climate friendly goods and services" focusing on the 43 products identified by the World Bank (2008a) as well as services that, "could contribute to [Member's] efforts to address climate change". The joint proposal also called for a second phase of the liberalization process involving negotiation of an "Environmental Goods and Services Agreement" (European Commission 2007; Mytelka, 2007; see also EU 2007; Mandelson 2006; USTR 2007). Some developing countries raised concerns about 'dual use' issues and others suggesting that the proposal represented a 'disguised effort' to gain access to developing country markets for developed country goods and services (Mytelka, 2007).

As in the case of IPRs, it will be vitally important to develop a workable division of labour for each of these intersecting areas between the international climate policy regime and the multilateral trading regime. Explicit attention should be directed to this institutional dimension during the Copenhagen process in order to avoid redundancy and confusion.

\subsection{Technology partnerships, agreements and sectoral approaches}

The idea of technology agreements for climate change is the subject of a growing literature (e.g., Ott, 2005; 2007; Alfensen, 2007; de Coninck et al., 2008a etc.). The elements constituting such agreements are broad and differ from author to author, but generally include binding and non-binding sectoral agreements for industry, financial tools, joint R\&D, demonstration projects, information sharing arrangements, etc. The discussions of sectoral approaches can generally be separated between those that would interact with the carbon market (baseline and credit, 'no-lose' targets, crediting of national appropriate mitigation actions, etc.), and those that have a more specific technology approach that is either not appropriate for a market based system, or for those technologies that are unlikely to be implemented solely by a revenue incentive. The challenge in most cases is to codify these actions and quantify their impact in some coherent way. The focus of this paper is to consider some of the 'non-carbon market' agreements.

Current international collaboration including: The Carbon Sequestration Leadership Forum (CSLF), the Methane to Markets, Global Gas Flaring Reduction, ITER, IEA Implementing Agreements, and the like. The Asia Pacific Partnership focuses specifically on technology issues and considers bilateral and multilateral partnerships in specific sectors (through eight separate 'task forces'). Sugiyama (2005) describes a multitude of synergistic technology agreements under a macro-framework called the General Agreement for Climate Technology (GACT). Egenhofer (2007) and Milford (2007)) propose a “consultative group on climate innovation”. They recommend that the EGTT, as one of several groups, be part of a wider coordinating network, and call for technology specific approaches with a "bottom-up, open and distributed innovation" focus. ${ }^{39}$ This distributed innovation proposal suggests some organisational arrangements and a fund. Similarly, the Global Leadership for Climate Action recommends creating a Consultative Group on Clean Energy Research (GLCA, 2008). Marlay (2008) offers a large array of areas for possible international R\&D collaboration ranging from fuel cells, to zero emissions vehicles to aspects of CCS.

Baumert (2002) uses national case studies to consider specific methodologies that might be useful in future climate change architecture(s). The book considers a framework for considering

39 Some of the climate-specific innovation literature (like that cited here) seems to focus on 'breakthrough' technologies and systems. While valid, this approach could only form one aspect of a wider suite of interventions. 
various approaches based on coverage, timing, approach to differentiation, legal nature, and other fundamental elements. This includes consideration of SD-PAMS (Baumert, 2005), dynamic targets, sectoral CDM, per-capita based entitlements, etc. EC (2005b) highlights four elements of a future agreement. Likewise, Pew Center (2005) describes elements of 'parallel' efforts including technology cooperation.

De Coninck et al. (2007) discuss aspects on technology oriented agreements (TOA) and their relationship to emissions trading. They note, "The question is whether technology- or sectororiented types of agreements can be designed in such a way that they can lead to real and measurable reductions in emissions. Existing technology agreements are known to have stimulated research and development (by providing a 'technology push'), but examples of such agreements solving environmental problems (for which a 'technology pull' is also needed) are sparse." De Coninck et al. (2008a) provide a typology of four types of TOAs: knowledge sharing and coordination, RD\&D, technology transfer, and technology mandates, standards and incentives. Usefully they also consider the difference between the engineering and the economic perspectives on the topic.

Like TOAs, sectoral agreements are also often referenced when considering the nature and scope of a post-2012 regime, most often as a way to, inter alia, engage a wider community and may accommodate competitiveness concerns in key industries. Bradley (2008) concludes that a sectoral approach is not desirable on its own, but could be used 'with caution'. The caution is in the areas of information asymmetry, losing focus on the main priority (limiting emissions, and separating out certain sectors from competition from new lower-carbon industries). Finally they note that different Parties are using different meaning for the word 'sector'. Bradley (2008) notes that it is more useful to describe specific actions such as, "....sectoral crediting, mandatory sector emission caps, technology standards...” Sectoral work is also discussed in Baron (2007) and Schmidt (2006). Baron (2007) describes four possible manifestations:

- Country-specific quantitative approaches:

- Sustainable development policies and measures (SD-PAMS)

- A trans-national quantitative sectoral approach.

- Technology-oriented approaches

Baron (2008) considers how to best integrate sectoral approaches into a Copenhagen Agreement. The eligibility criteria and the links between national actions (NAMAs), or crediting of some kind (linked to CDM, no-lose, etc.) are cited as key areas to negotiate into COP15 text. Baron (2008) goes further to suggest that sectoral structures could act as an 'organising principle' for the technology aspects of the negotiations, and could allow for robust MRV. But for COP15, he proposes all that would be needed is an identification of pilot sectors and countries, a timeline, and guiding principles.

This paper focuses primarily on the SD-PAMS and TOA aspects, as more generic sectoral approaches have more in common with economic instruments and are less likely candidates in an enhanced technology framework. There are questions with regard to how technology and sectoral agreements or SD-PAM would co-exist with economic instruments such as a cap-and-trade agreement. Nordhaus (2003) gives a perspective of how standards for efficiency could be utilised in coordination or in parallel with a cap and trade programme. Buchner and Carraro (2005) uses an augmented game theoretic augmentation of the DICE model (Nordhaus, 2007) to consider what a global technology protocol might look like. They conclude that a technology agreement with no binding target, while having some economic benefits, would not provide the requisite emissions reductions or the reciprocity required to stabilise the coalition.

The EC SET Plan (2007) and the US CCTP (2006) are examples of approaches to developing a suite of energy technologies from a R\&D perspective. The SET Plan focuses on: industrial initiatives (where the private sector leads and interacts on strategic issues with the governments), a platform for energy efficiency, dialogue between research centres, capacity building, and 'cove- 
nants' (agreements) between countries. The US and EU plans have substantial funds allocated but these are insufficient to advance all the technologies needed. Although they cover many energy technologies, their coverage in the transport and buildings sectors is weaker.

Energy efficiency (EE) is a complex and essential area that needs to be targeted by any future treatment of technology in the UNFCCC. The importance of this area of energy policy has been widely considered, and it is referred to in a number of other sections of this paper. IEA (2008b) is an excellent reference for key policies in the EE area separated into seven priority areas: cross-sectoral activity, buildings, appliances, lighting, transport, industry, and power utilities. IEA (2005b) and Likewise, Harmelink (2007) both provide evaluation of (primarily OECD) policies for EE. Some of the policies referred to in Harmelink (2007) might be applicable under the UNFCCC framework in some way, such as: provision of energy audits, voluntary sectoral agreements, information/education/training, performance standards, labelling, etc. Although demand-side energy efficiency technologies are eligible under the CDM, to date the take-up in that area has been low ${ }^{40}$. Although programmatic $\mathrm{CDM}^{41}$ is being investigated as potentially well-suited to EE policies (Hinostroza, 2007), it may benefit from being linked to a technology framework $^{42}$ in order to appropriately stimulate the market (especially households and SMEs). Given the specific barriers, finance situation and market failures that EE faces, a simple cash flow signal will unlikely be sufficient. This paper recognises that many interventions, including for example, energy efficiency standards for buildings, appliances and transport, would likely need to be dealt with outside of the UNFCCC.

\subsection{Sustainable Development Policies and Measures}

The literature shows that with a well constructed policy environment, public sector costs of supporting low carbon technology decreases as private sector participation increases. Generally, governments can improve the cost-effectiveness of low carbon options through one or a combination of the following (Anderson, 2006):

- Directly raising the price of carbon (price or quantity instruments) and so increasing prices for competing higher carbon fuel technologies.

- Indirectly pricing carbon by raising prices paid for low carbon outputs.

- Reducing private (investment) costs and/or guaranteeing market demand.

These options allow the burden of higher costs and risks to be shared between the public and private sectors. IEA (2008c) highlights how different policy incentives have worked to lower the costs of renewable technologies. The IEA study, like many similar studies, emphasises how non-economic barriers impact on the success of policy incentives irrespective of their design, and draws attention to the importance of the country-specific context.

SD-PAMs are policies and measures designed primarily to achieve domestic development goals that are shaped to set key countries and sectors on lower-carbon development paths. They were first described in the context of climate policy by Winkler (2002) and have become a staple of the climate policy vocabulary, proposed by both governmental (South Africa, 2006) and nongovernmental (CAN, 2003) actors. By defining actions that bring together both sustainable development and climate goals they explicitly address the central objective of the UNFCCC (1992, Article 2), a link that is explored by Metz et al. (2002).

Considerable additional work has been done in defining SD-PAMs, (Bradley and Pershing 2005; IISD 2005; Gupta et al. 2007), and in exploring how they might be incorporated into international agreements (Baumert and Winkler, 2005; Ellis et al. 2007; Lewis and Diringer, 2007). In the technology context they may prove useful helping to define what exactly is meas-

40 Energy demand cited as $1.22 \%$ on http://www.unfccc.int 2.9.08.

41 EB 32, Annex 38, Paragraph 1.

42 In order to specifically address the regulatory, policy, and capacity barriers inherent. 
ured, verified and reported by developing country Parties. Specifically they might also prove useful as ways to draw boundaries around areas like policy-related EE actions. They are also useful in relation to defining certain technology agreements or sectoral approaches.

As currently conceived, SD-PAMs are not necessarily framed around technology deployment. They may involve other means of delivering the development goal, whether through institutional reforms, behavioural changes or improved resource management. However, in many cases the achievement of development goals on a lower-carbon trajectory will be based on technology deployment. SD-PAMs can play an important positive role by supporting effective actions on technology. The most important factor in allowing new technologies to be deployed effectively is the presence of consistent supportive policy structure. SD-PAMs, as policies and measures rooted in national development interest, could provide this kind of environment. Furthermore, since SD-PAMs are integrated within the range of a country's development priorities within a country they potentially offer a means to integrate mitigation and adaptation concerns in framing technology choices.

A number of studies have explored specific instances of SD-PAMs that enhance technology adoption. The literature is particularly rich in consideration of the power sector, in both electricity demand (Winkler et al., 2006) and supply (Dubash and Bradley, 2005; Höhne and Moltmann, 2008; Winkler et al., 2008). These conclude that there are significant actions that can be undertaken that use deployment of clean and efficient technologies to achieve both development and mitigation goals. Transport is another sector which has received attention, with similar conclusions (Moreira et al., 2005; Ng and Schipper, 2005).

There are some limitations to the role of SD-PAMs in supporting technology deployment. Because of the emphasis on national sustainable development interest, some technologies will be far less amenable to deployment under SD-PAMs than others. This will depend on how large the local development benefits of those technologies are relative to the global benefit of reduced GHG emissions. For instance, Mwakasonda and Winkler (2005) conclude that $\mathrm{CO}_{2}$ capture and storage technology is difficult to justify for South Africa on national development grounds, and would require other kinds of support.

The SD-PAMs model is the precursor to 'nationally appropriate mitigation actions' (NAMA) for developing countries in the Bali Action Plan (Para 1.b.ii). These are to be supported 'in a measurable, reportable and verifiable manner' by finance, technology and capacity building form developed countries. What exactly the technology component of such support consists of has yet to be defined, but the literature on technology related to SD-PAMs will be important in informing this discussion. The elements of an 'enabling environment' for technology discussed in Section 4.1 are also needed to support the effective implementation of SD-PAMs. By the same token, SD-PAMs can also help create an enabling environment for technology transfer. Winkler et al. (2007, 2008) have explored some of the issues related to 'measurable, reportable and verifiable' in the context of SD-PAMs, but further work still needs to be done on the technology support for such measures.

\subsection{Finance for technology}

Finance is central to the UNFCCC discussions on technology. Financing is mentioned in the first paragraph of the technology section of the Bali Action Plan as, “...provision of financial and other incentives for, scaling-up of the development and transfer of technology...” Likewise, under the Finance section of the Action Plan, technology is referenced in the opening sentence (1(e)). The two fundamental analytical tasks (see FCCC/SBSTA/2008/INF.2) in the finance ar- 
eas have been to quantify the amount of funding required under different stabilisation scenar$\operatorname{ios}^{43}$, and then determine what gaps exist in amounts and instruments required.

\subsubsection{The scale of the investment opportunity}

When considering scaling-up of investment in low carbon technology, the typically higher capital costs and risks associated with newer technologies tend to be the principal barriers. The short-run marginal cost of energy produced is also likely to be higher than existing sources.

Stern (2006) notes, “Our modelling suggests that, in addition to a carbon price, deployment incentives for low-emission technologies should increase two to five times globally from current levels of around US\$33 billion....Global public energy R\&D funding should double, to around USD20 billion, for the development of a diverse portfolio of technologies.” The IEA (2008a) estimates that deployment $\operatorname{costs}^{44}$ for the BLUE Scenario would be on the order of US\$ 10.4 trillion from 2005-2050.

The UNFCCC (2006, 2007) and authors like Noro (2007) have provided a global picture of the instruments used for financing of climate change mitigation and adaptation. The fundamental finding shows a need for 'additional and changing' patterns of financial flows to combat climate change (in mitigation). UNFCCC (2007) provides a view of the changing picture over the decades from 2005 to 2030 separated by technology and under two scenarios (Figure 4.2) ${ }^{45}$. IEA (2008a) also provides various technology-specific financial requirements.

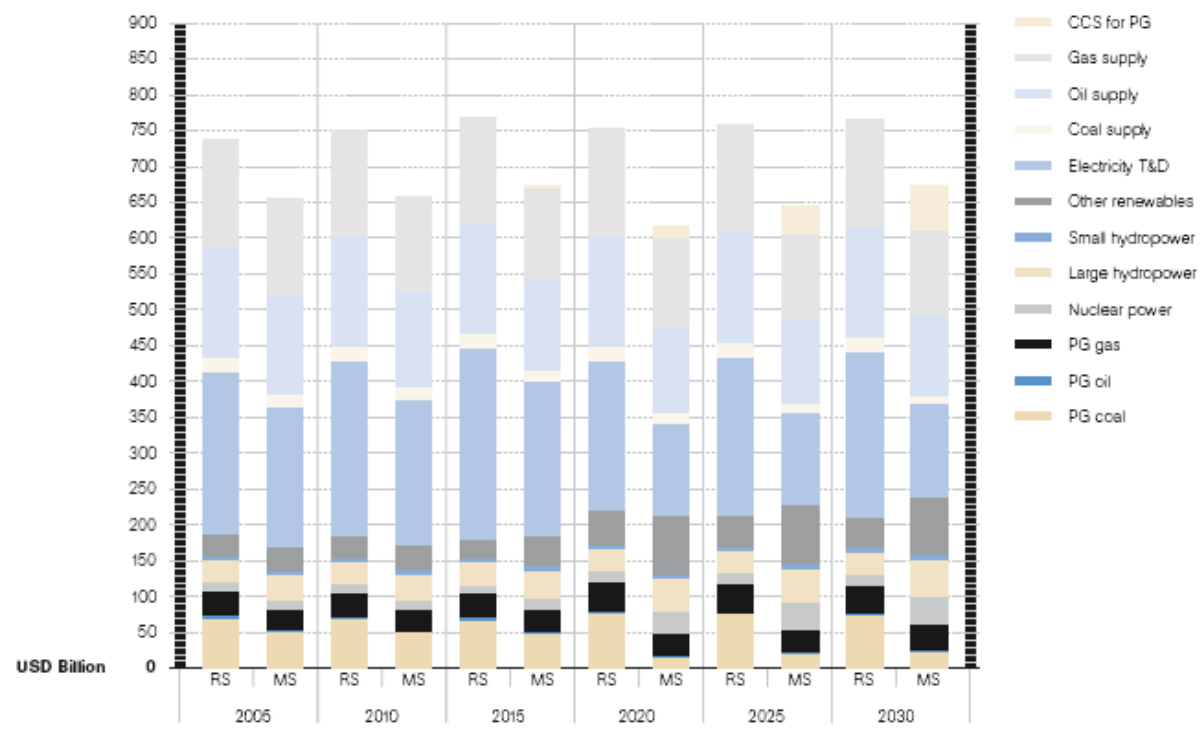

Figure 4.2 Overall technology finance needs

Source: UNFCCC, 2007.

43 The UNFCCC (2007) provides a headline figure of USD210 billion additional required (annually) by 2030 for mitigation. The IEA WEO (2007) shows a requirement of USD22 trillion for the energy sector to 2030 (cumulatively), the IEA (2008) ETP cites the need for USD45 trillion over a BAU case to 2050 (cumulatively). Interestingly, Chapter 34 (sub 29) of Agenda 21 states "The Conference secretariat has estimated the average total annual cost (1993-2000) of implementing the activities of this chapter to be between USD450 million and USD600 million."

44 Defined as, "total costs of cumulative production needed for a new technology to become competitive with the current, incumbent technology.”

45 The reason why the investment numbers in the Mitigation Scenario are lower than in the Reference Scenario is that this includes energy supply sector only investments. Strong energy efficiency measures lead to lower energy demand and lower investments in the energy supply sector. Overall energy investments however, are significantly higher in the Mitigation Scenario because of higher energy demand investments. 
Stern (2006) also provides an idea of the scale of public expenditure required in the short-to medium term (Figure 4.3), and compared with current fuel subsidies. There is a wide literature on energy subsidies and their forms and impacts (e.g. IEA, 1999, 2006; OECD, 2002; Stern, 2006; 2007; IEA, 2008a). Morgan (2007) states that in the energy sector they are on the order of, "US\$ 250 to US\$ 300 billion per year net of taxes worldwide, equal to $0.6 \%$ to $0.7 \%$ of world GDP..." The vast bulk of that amount goes to fossil fuels (around USD200 billion), half of which to oil, and about US\$ 30 billion to low-carbon technologies (half of which to nuclear). It is clear that addressing energy subsidies can have an enormous impact on the portfolio of energy technologies, especially in Russia, Iran, China, Saudi Arabia, and India (IEA, 2006). This needs to be more explicitly part of the UN negotiations since it has distortionary impacts on energy and carbon markets, infrastructure investment, energy demand, R\&D prioritisation, and of course emissions $^{46}$. If the tools used for energy subsidies (grants, loans, tax measures, R\&D, infrastructure investment, demand guarantees, price controls, etc.) can be realigned with climate change priorities then they could be very influential in moving towards a low-carbon sector ${ }^{47}$.

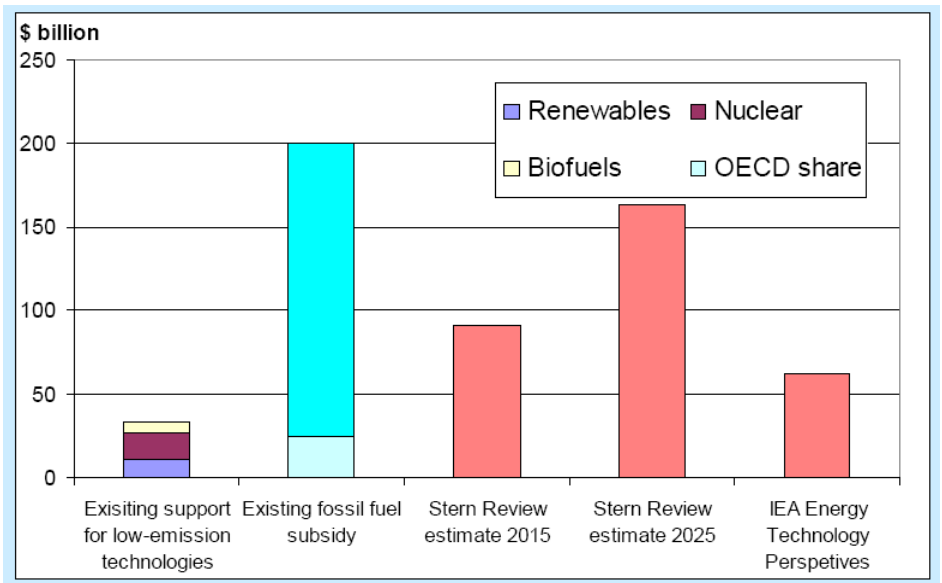

Figure 4.3 Scale of public technology development support needed

Source: Stern, 2006.

The private sector has recently shown a large appetite for investment in renewable energy technologies. Figure 4.4 shows the growth in investment by financial category ranging from venture capital through to government R\&D to asset financing. This growth continued in 2007, with approximately USD148 billion of new money invested globally in sustainable energy companies and projects, an increase of $60 \%$ over the 2006 value (UNEP 2008a). Also notable was the continuing trend toward investment in large developing countries (UNEP, 2008b; UNEP, 2008c).

46 IEA (1999) found that the removal of energy subsidies in 8 non-OECD countries would reduce demand by 13\%, increase GDP by $1 \%$, and lower $\mathrm{CO}_{2}$ emissions by $16 \%$.

47 It is important to recognize the political barriers to subsidy removal and the need for international mechanisms to help national governments overcome it. The long-term benefits of subsidy reform need to be clearly defined. 


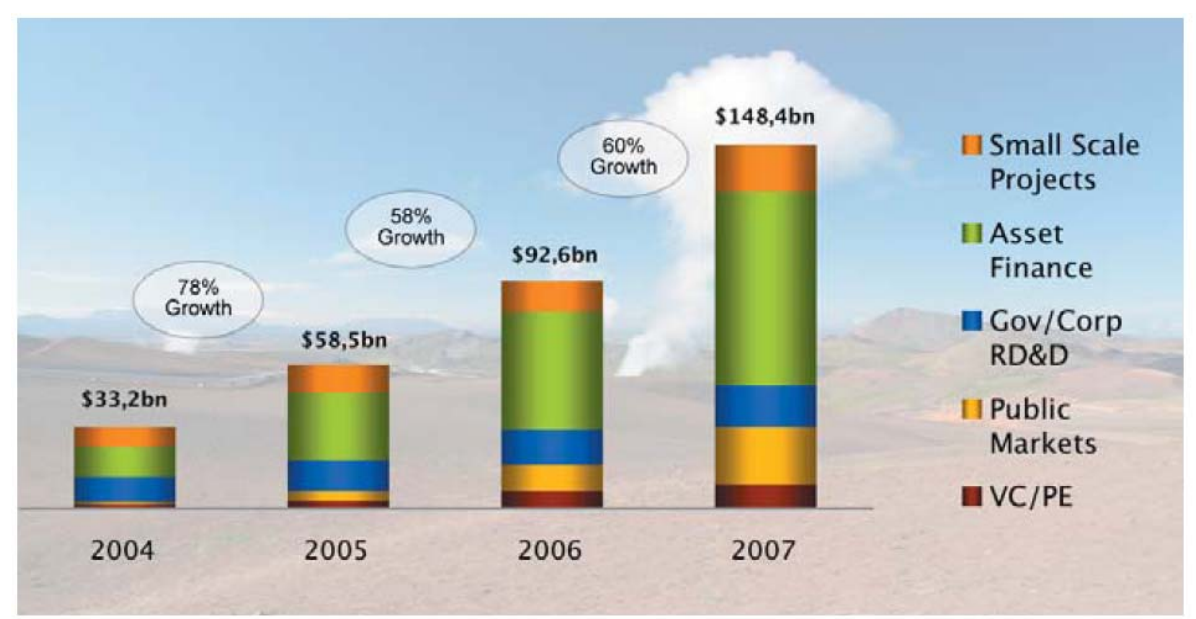

Figure 4.4 Sustainable energy investment by category 2004-2007

Source: NEF for UNEP, 2008a.

The NEF helps identify those points along the financing continuum where attention needs to be focused. It is clear that asset financing is the bulk of investment in the clean energy area. The venture capital (VC) and private equity (PE) space is critical for technological development and commercialization. But the number of technologies and technology companies going on to Initial Public Offering (IPO) is significantly smaller than the number considered by the VC/PE space, indicating that only a small number of these are actually moving beyond what has been called the 'valley of death'48 (NEF, 2007).

\subsubsection{Specific financial barriers in developing countries}

Designing, implementing and enforcing incentives for low carbon energy investment implies additional costs to the public sector and new demands on institutional capacity. IEA (2008) shows that non-OECD countries make up the bulk (97\%) of (energy-sector $\mathrm{CO}_{2}$ ) emissions growth to 2030, under business as usual (BAU) conditions those non-OECD emissions would exceed a global 450 ppmv trajectory. This scenario demonstrates the need to ensure implementation of low-carbon technologies in developing countries. The World Bank estimates the additional costs of low carbon energy technology in developing countries to be between USD25-50 billion/yr (Watson, 2007). This number roughly corresponds to the public finance required unless other policies are implemented. The IEA (2008a) estimates that around $60 \%$ of the additional investment needs (over a baseline) occurs in non-OECD countries. The structure of financial markets and limited availability of suitable forms of finance is a common barrier within developing countries, notably:

- Scarce availability of capital for public investment means that governments are reluctant to divert resources away from pressing social and economic needs.

- Investments in renewable energy and energy efficiency in developing countries can result in significant long term cost savings in terms of reduce fuel costs and energy security, however, financial instruments are not structured to take account of these longer term benefits.

- The structure of capital markets tends to constrain private investors, whereby required rates of return disfavour high capital costs. Where capital is available, investors may be deterred by poor credit-worthiness of potential project developers and the lack of guarantee facilities.

- Lack of access to appropriate forms of credit can be a particular constraint for smaller scale renewable energy developers. Similarly, availability of micro-credit for customers is necessary to sustain energy efficiency service business models.

48 This is a commonly used term to describe the part of the technology development cycle where many products fail to secure sufficient investment to move to later stages towards commercialisation (Murphy and Edwards, 2003). 


\subsubsection{Gaps and instruments}

Overcoming these financial barriers requires greater availability of, and access to, low cost investment capital. This can either be used directly by governments to invest in low carbon infrastructure or, as highlighted earlier, to create policy incentives designed to leverage private investment. Financial resources may be channelled through local or intermediary financial institutions, whether public or private, to make credit services and guarantee facilities more widely available ${ }^{49}$

The technology development continuum (Grubb, 2004) includes an often cited schematic of the 'innovation chain' is augmented with a financial continuum (Figure 4.5) in work by the ADB (2007). Schrattenholzer (2003) provides another useful schematic of the interaction of R\&D and learning with other institutional and regulatory effects. Likewise, UNEP (2005) detailed a different financing continuum for both large and small projects, and compared the type of financing needed with necessary support provided through the broader enabling environment ${ }^{50}$. Importantly UNEP highlighted typical financing gaps and proposed remedies, ranging from seed capital funds to banker training programmes to financial transaction support mechanisms. Different barriers arise along successive stages of a project's (and a technology's) development, and remedies must be specifically tailored to these barriers. It is important to note again that innovation is only pictured as a linear process, with neatly distinguished, sequential steps as this helps structure thinking about the process. In reality, innovation is a complex and chaotic process, with policy and finance institutions interacting with technological developers, and with R\&D still taking place for mature technologies to provide incremental improvements of earlier concepts. Also, the systems into which technologies are embedded require development and constant refinement (i.e. development of infrastructure and trading markets, etc.).

49 Zaelke (2007) sets out the relevant aspects of the possible synergies in instruments from the Montreal Protocol. Importantly the MP gives financial assistance to cover incremental costs of developing countries in implementing technology. This financial assistance also includes aspect of capacity building, training, in-country support offices, regional networks, etc. and has thus far been at a level of about US\$ 2.5 billion (since 1991). The fund is governed by an Executive Committee whose 14 members are drawn equally from both developed and developing countries. The funding is enhanced by trade restrictions and non-compliance penalties (see also: Anderson, 2007).

50 An EU sponsored programme called FUNDETEC (2008) identified funding mechanisms for environmental technologies in the private and public spheres. The report queried a large amount of funding types (ranging from equity instruments, to debt instruments, to grants), and provides significant detail on different classes of financing, the users, the case studies, etc. 


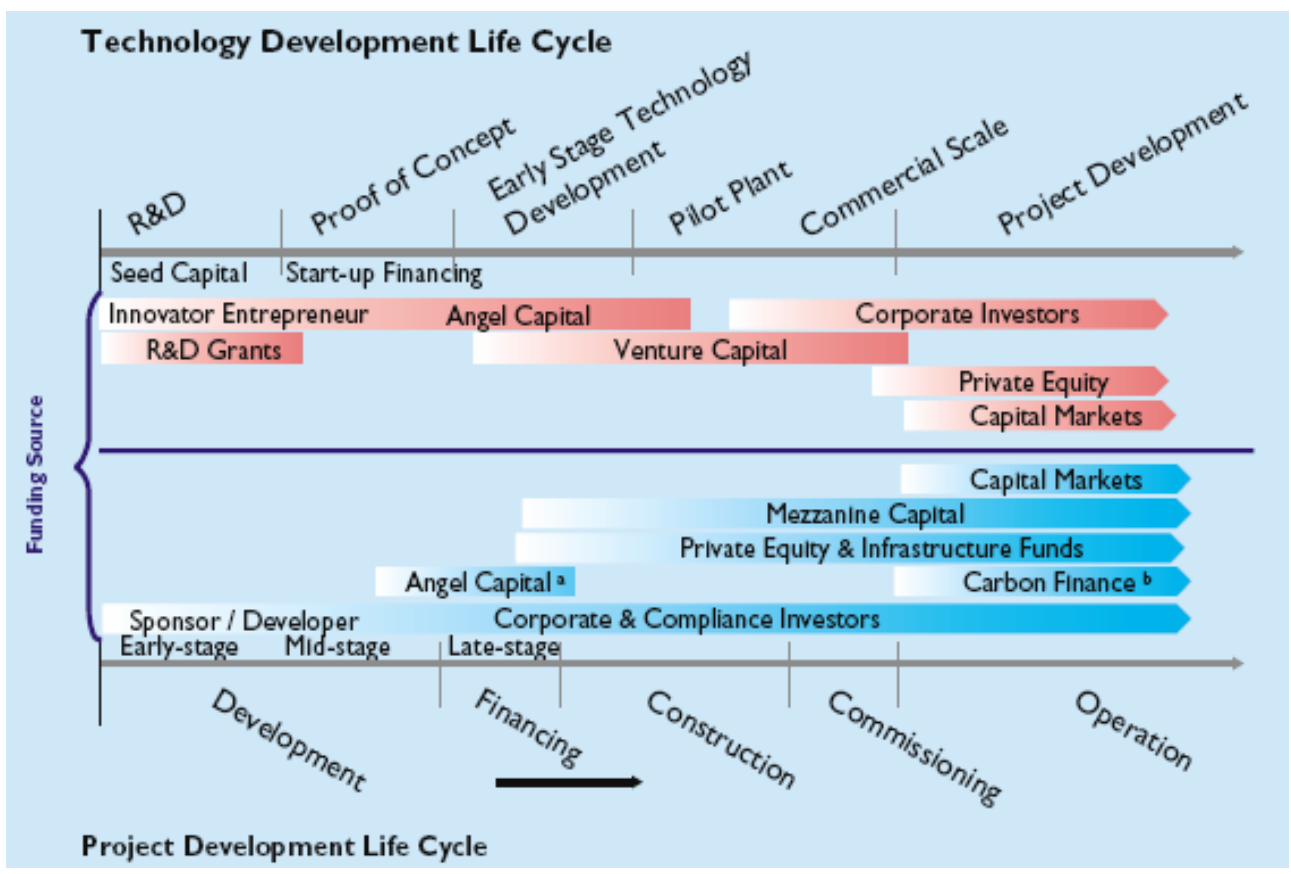

Figure 4.5 Technology development life cycle schematic

Source: ADB, 2007.

UNEP (2004) has categorised the risk management instruments that could be usefully employed to improve the investment environment in the clean energy area. The report highlights twelve risk instruments that could be applied to different technologies and financing structures including: guarantee funds, export credit guarantees, contingent capital, weather derivatives, mutualisation structures, etc. UNEP (2005) also alluded to risk instruments such as: changing risk rating methodologies, extending existing insurance products to climate technologies. Murphy (2003) argues that an enterprise strategy should include elements of information provision, networking, and incubators.

The principle vehicles under the UNFCCC associated with financing for technology are the carbon market (and specifically the CDM market), and the Global Environment Facility (as the UNFCCC financial mechanism). Of the CDM market, Seres (2007) notes that, "Roughly 39\% of all CDM projects accounting for $64 \%$ of the annual emission reductions claim to involve technology transfer....Technology transfer usually involves both knowledge and equipment with equipment imports accounting for most of the remaining transfer.” De Coninck et al. (2008b), Haites et al. (2006) and Dechezleprêtre et al. (2008) also consider technology transfer aspects of CDM and arrive at roughly similar results. The exact benefits, however, remain somewhat difficult to quantify.

As noted at the outset of this paper, internalising the cost of carbon, whether directly or indirectly, is a necessary but insufficient condition to provide the impetus for technology development and deployment required. Stern (2006) cites several reasons for this, including uncertainty in timing and policy and near-term access to capital markets. The Kyoto Protocol's CDM has been relatively successful at attracting both finance and technical assistance for project specific investments in commercially available technologies. However, the current project-based approach has been insufficient in fostering the policy changes needed to deliver the scale of investment required for deployment of existing technologies, let alone provide the stimulus for investment in technology development and demonstration.

In the medium to longer term (2030-2050), greater volumes of carbon finance, and the evolution of programmatic and sectoral approaches, imply a much greater role for the carbon market in overcoming financial barriers and delivering scale of investment. In the shorter term attention 
must be focused on how to ensure existing financing resources and instruments are deployed most effectively. Thus, this paper focuses on the intervention elements outside of the carbon markets.

Decision 4/CP.13 outlined several mechanisms for financial support (largely outside of the carbon markets) to be considered by Parties for technology development and transfer:

(a) The implementation of technology needs assessments

(b) Joint research and development programmes and activities in the development of new technologies

(c) Demonstration projects

(d) Enabling environments for technology transfer

(e) Incentives for the private sector

(f) North-South and South-South cooperation

(g) Endogenous capacities and technologies

(h) Issues associated with meeting the agreed full incremental costs

(i) Licenses to support the access to and transfer of low-carbon technologies and know-how, and

(j) A window for, inter alia, a venture capital fund related to, or possibly located in, a multilateral financial institution

UNFCCC (2007) notes that the GEF as, “...an operating entity of the financial mechanism of the Convention, has allocated over US\$ 3.3 billion to projects addressing climate change since its inception (1991), with further co-financing of US\$ 14 billion. Most of the funding has been for renewable energy and energy efficiency projects.” The GEF mandate can be refined and augmented in a future framework. Its work in climate change has a clear technology focus. GEF (2008) notes, "In the time it has existed, the GEF has financed the incremental costs of climate change mitigation projects supporting the transfer of at least 34 different ESTs." It also presents the concept of funding technology market assessments (TMA) that would be a follow-on activity from technology needs assessments (TNA). There is still the need to focus on the provision of robust TNAs prior to moving to other assessments or determining the optimal mix of support and its sequencing.

Since 2005, particular attention has focused on the role of the Multilateral Development Banks (MDBs) as providers of public finance in the form of loans, grants and guarantees for energy infrastructure investment within developing countries (World Bank, 2006a). A number of existing MDB financing instruments and services have been deployed to deliver technology investment objectives, and the following are examples of potential instruments that could be deployed:

- Policy-based lending and provision of finance and expertise for identified domestic policy objectives, including the design of low carbon policy incentives and necessary institution building ${ }^{51}$.

- Loan guarantees to local financial institutions to support debt and equity lending to commercial investors.

- Debt financing to free up public resources that can then be directed to low carbon policy objectives ${ }^{52}$.

- Risk sharing mechanisms

- Equity investments used to establish revolving funds to mobilise public and private sector funds for making available appropriate capital and financial services.

- Providing guarantees or loans to energy service companies (ESCOs)

- Offering micro-credit and energy services to customers.

- Grants used to support applied RD\&D

- Seed-capital for start-up costs of public-private ventures.

\footnotetext{
51 As an example, the Mexican Government is currently working to implement a national climate change strategy with such support from the Inter-American Development Bank.

52 Similar to the experience of 'debt-for-nature' swaps (Deacon, 1997).
} 
Examples of instruments that have been developed include: EIB's (2007) Risk Sharing Finance Facility (RSFF) as example of finance directed at specific technology development. The World Bank's Multilateral Investment Guarantee Agency (MIGA) ${ }^{53}$ provides risk insurance to promote FDI through three main areas: political risk insurance, technical assistance, and dispute mediation. Experience shows that even where such options have been utilised, they have been insufficient on their own and need to be coupled with technical assistance designed to build the relevant capacity of policy makers, local finance institutions and businesses in order to overcome non-financial barriers.

Despite the opportunities provided, uptake of such financing instruments for low carbon investment has been relatively limited. In July 2008, the MDBs (2008) identified the need for new concessional funding in the form of direct grants, low cost (subsidised) loans and guarantees to make the above instruments more attractive to developing countries. In response, on 26 September 2008, a number of donors pledged around US\$ 6.1billion for the clean investment funds (CIF), US\$ 5 billion of which is allocated to the Clean Technology Fund (CTF) and can be accessed through the MDB implementing agencies for the CIFs.

Tailored financial packages, whereby CTF concessional finance is blended with nonconcessional MDB finance to reduce the costs and risks associated with low carbon technologies, should help make the financing instruments referred to above more attractive options for policy makers. At the same time, the CTF will help to leverage greater levels of existing MDB finance towards low carbon investments. As CTF funds become available in early 2009, they can fill an immediate financing gap to mobilise public and private finance.

The link between the work of International Financial Institutions and the UNFCCC requires further exploration. What is clear, however, is that the MDBs can do more with their resources and technical expertise to help developing countries establish 'enabling environments' for the deployment of clean technologies, and to explore options to harness clean technologies to meet development needs such as access to energy. All of these areas could be aligned with goals under the UNFCCC more closely and provide enormous benefits; WRI (2008), for instance, suggests that greenhouse gas accounting and the incorporation of a 'shadow price for carbon' into investment appraisals can support such practices. Any enhanced treatment of technology in the UNFCCC needs to be closely aligned not only with sources of funding but as well with the needs of recipients and specific technology-focused financial tools.

53 http://www.miga.org. 


\section{A conceptual framework}

A number of criteria for considering technology in the UNFCCC are presented in this section. An outline of an enhanced technology framework that meets these criteria is then presented, along with some guidelines for measuring success.

\subsection{Criteria for a conceptual technology framework}

Criteria have been derived from the literature, and the six elements addressed in Chapter 4 . If these conditions are not met, it is unlikely that the treatment of technology will be effective in overcoming barriers and ensuring investment. Criteria that should be satisfied include:

- Self-reinforcing: An enhanced technology framework should be designed so that it enhances outcomes by rewarding, through reciprocity, those Parties who meet the necessary performance conditions or benchmarks. A reflexive, self-reinforcing framework is critical in facilitating sufficient participation and promoting adaptive learning going forward.

- Environmentally effective: The framework should favour technologies that have a long-term potential for deep emission reductions, and should ensure that spill-over and ancillary environmental impacts are minimised or are positive. The framework should achieve a sufficient scale to make step-changes in technologies (rather than rely solely on incremental change).

- Alignment of sources of financing with technology and country needs: Low-carbon technologies will need financing specific to the context of the technology and of the country where the technology is to be realised. Accordingly, the framework must facilitate careful attention to the effort to align funding with technology and country needs, including via international collaboration on commercial-scale demonstration projects for key technologies. The framework should also ensure complementarity with existing and emerging funding efforts outside of the UNFCCC context (and vice versa).

- Appropriate financing structure: Targeted financial structuring can help make the framework cost-effective by optimising risk coverage through various finance instruments and products. The framework should have built-in features that look for the optimal use of public funds for leveraging private sector finance.

- Enabling environment: All aspects of an enabling environment, including a functioning market economy, are essential for technology advancement and transfer. The framework should recognise and honour this.

- Demand-driven: Addresses the clearly identified and argued needs of recipients and builds upon sound, existing local policies (and ensuring alignment with global requirements).

- Coordination with relevant IPR and trade regimes: Identifies and promotes removal of tariff and non-tariff barriers to technology transfer in the appropriate fora. Promotes adaptive, evidence-based discussions in the appropriate fora on IPRs, and identifies and promotes expanded capabilities to detect and remedy restrictive IPR licensing practices, while avoiding approaches that would undermine the positive role that IPRs play.

- Prescription versus specificity: Allows for a flexible and adaptive approach to the choice between technology-neutral and technology-specific policies and measures depending on the particular context. Any approach should make use of market efficiencies but credibly address market failures.

- Easy to implement: the administrative requirements and transaction costs should be reasonable and justifiable given the level of effort.

- Measurable, reportable, verifiable: The results of the framework should be measurable, reportable and verifiable which should extend to both measures taken under the Convention and those taken outside of the Convention. Measurement, reporting, and verification should be transparent and accountable. 


\subsection{Contours of a conceptual technology framework}

We attempt to connect the criteria developed to shape aspects of an internally consistent conceptual technology framework. This framework remains consistent with a market-based economy, and specifically addresses the challenge of providing technology and finance for developing countries in a way that would be acceptable for industrialised countries. The self-reinforcement is provided through the gradually increased vested interest in further diffusing the technologies that are adopted. The interests increase gradually through a step-wise, circular process that rewards compliance. We will also suggest, based on very rough estimates, the order of magnitude of total funding that would be required for each step.

The first element and the basis of the conceptual technology framework is the enabling environment. Informed by TNAs and NAMAs (guaranteeing that the framework is demand-driven), developed and developing countries cooperate to articulate and then attain certain milestones in the enabling environment. This involves funding a human and institutional capacity building programme, and potentially creating an innovation centres establishment fund. More specifically, it could mean:

- The establishment of an Institutional Capacity Building Programme to assist the National Climate Change Focal Points ${ }^{54}$ (NFPs) and Governments in mainstreaming climate change objectives within national policies, relevant capacity building, and strengthened operational links between the NFPs and relevant line ministries and government units. A key element of such capacity building should be to build meaningful operational links between the NFPs and relevant line ministries and government units in their countries. For the purposes of technology transfer for mitigation, linkages with agencies involved in (a) planning (b) energy and electricity (c) science and technology are particularly relevant. Another feature of such a programme should be to facilitate networking among NFPs to enhance the sharing of knowledge and experience, an approach that has proved very helpful in accelerating national actions under the Montreal Protocol. Such networks could be established on a regional or subregional basis.

- Technical assistance and support for transparent and inclusive integrated resource planning ${ }^{55}$ at the national and sub-national levels in an accountable manner. Such measures should strengthen relationships between technical bodies and policy-makers, and strengthen the technical capacity of planners and other decision-makers to understand the implications of climate change and the options for addressing it. Technology options assessments would be a key component of such initiatives. NFPs may be able to work with government agencies and planning units in creative ways to support more effective implementation of such planning processes.

- Support to strengthen regulatory agencies capacity for overseeing key sectors and industries and for considering and implementing proactive measures that support the deployment of climate friendly technologies at the national and sub-national levels in ways that are fair and effective to meet local needs. For example, clear guidance to utilities requiring transparent analyses of various generation and efficiency technology options to meet projected energy needs could be required. In this context, efforts to expand the legal mandate of regulatory institutions to consider environmental issues such as climate change should also be supported. An important element of this support would be helping developing countries reform energy subsidies that encourage over-consumption of fossil fuels.

- Efforts to build the capacity of non-state independent actors (such as consumer organisations and independent research institutions) to monitor the design and implementation of policy and regulatory frameworks for key sectors to demand that climate change considerations are reflected in decisions consistent with local needs and priorities.

54 Details on these NFPs are on: http://www.unfccc.int.

55 This term, IRP, often is used in the electricity sector prior to market liberalisation, but can be used much more widely. 
It is extremely difficult to estimate the annual costs associated with this first step, and this is an important area for further analysis. However we assert that the costs are likely to be considerably lower than the following steps.

Once a developing country achieves a milestone on implementing an enabling environment, in accordance with its technology needs and goals, it should be able to obtain access to public risk/equity (or other) finance that leverages private sector finance. This public finance could be provided by industrialised countries through a donation structure that remains to be designed. The likely required financing includes: an instrument for demonstration, a technology risk facility, and an information, network and support facility to overcome information and network barriers. The following considerations are central to this discussion:

- The bulk of the technology transfer to developing (and developed) countries is facilitated by the private sector, and likely to be increasingly driven by emerging carbon markets, including the CDM and possible evolution of programmatic and sectoral approaches. However, specific agreements may be necessary either to accelerate specific emerging technologies or to remove perverse incentives.

- Financing made available should be specific to the maturity of the technology being transferred and the market conditions under which the transfer occurs. Public funding and resources should be targeted to remove specific barriers that arise at different stages along the financing continuum. At the early stages, public funds could be used to support the development of projects that - because they are among the first of their type in a country - have a high demonstration value or help bring about systemic changes in the broader enabling environment. Technologies are provided through markets, and efforts should aim to develop and maintain the conditions under which robust markets for technologies can develop and grow.

- A special emphasis should be put on helping the diversity of actors that constitute the financial services sector to build their understanding of investment requirements of climate friendly technologies and the types of projects in which they are embedded. Banks and insurance companies tend to be risk-averse and reluctant to enter new fields without guarantee of returns on investment. Appropriately designed assistance is necessary to build understanding of new technologies and the different opportunities and risk profiles they present, and credit facilities and risk-sharing mechanisms may be necessary to encourage investors.

- Underlying all financing elements in the conceptual framework should be a strong emphasis on appropriately designed assistance for capacity building, networking ${ }^{56}$, and similar supportive efforts that develop and maintain critical human and institutional capabilities. It is important that the overall framework be comprehensive in its approach and not see financing elements as separate or distinct from those aimed at technology, institutions, or enabling environments. Multilateral development finance institutions can play a role in making such links. The framework would have a rich menu of supporting mechanisms and make more explicit links to funding provided through ODA, carbon markets, and commercial financial institutions.

Next, to strengthen the implementation of the technologies identified in the TNAs, technologyoriented agreements, sectoral agreements or SD-PAMs can be agreed. These set goals for technology implementation, trade and transfer ${ }^{57}$. They can be made technology-specific (e.g. in the case of large-scale demonstration, voluntary industry agreements, energy efficiency standards) and thus respond to the specific barriers or needs of a technology in a specific region. This is

\footnotetext{
56 The private finance advisory network (PFAN) offers a model being developed in this area (Storey, 2007).

57 One option for a technology approach could be a Technology Agreement on the F-gases. These gases fall under both the UNFCCC and MP. At the moment, the decisions on the amendments of the MP, and consequent financial arrangements, if promoting increased use of HFCs, may be working contrary to the general objective of the UNFCCC and against the countries efforts to reduce the emissions of GHGs. On the other hand, some decisions on CDM methodologies for HFCs, by giving perverse incentive to increased production of HCFCs, have already risked the overall objective of the MP and affected carbon markets. Also, depending on how the discussions and science and data progress in the area of black carbon, this area might be suitable for a separate protocol of some form as well.
} 
important as otherwise some technologies might be over-funded while others may not receive enough.

Technology agreements, sectoral approaches or SD-PAMs may be facilitated by technology assessments provided by an expert group functioning like the Technology and Economic Assessment Panel and its Technical Options Committees under the Montreal Protocol. Reporting to SBSTA, such a group would supplement in a broader and more flexible manner the special reports prepared by the IPCC (Andersen, 2007). Such assessments could also clarify the state of technology maturity and suitability, and hence clarify funding priorities within and across different technology sectors, including the optimum combination and sequencing of public and private sector funding.

As a suite of interventions, they would likely lead to more technology implementation and, likely, also trade and transfer of technology. This would require oversight to ensure equity and coherence. It is suggested that UNFCCC-administered (in coordination with outside expertise) technology panels could provide advice on the appropriateness of technologies. Issues related to IPR are also relevant. Potentially, a facility to address required royalties needs to be created. The facilitation of technology and sectoral agreements, and SD-PAMs would not likely cost more than several billions of dollars, as the financial framework is covered in the previous step.

The coordinating, management, monitoring, and other functions required might ultimately be designed under a myriad of different structures and organisations, both already in existence or created to facilitate specific outcomes. However, it is likely that some specific organisational interventions will be required. These might include:

- The UNFCCC should provide oversight to ensure environmental integrity and develop clear standards to make the technology targets measurable, reportable and verifiable.

- There could be a body to communicate with and accredit the multiple financial means for supporting development and deployment of technology, such as GEF, UN-system, bilateral donors, etc.

- All efforts that wish to be recognized as part of the UNFCCC technology framework could be reviewed by this body to assure the coherence, coordination and coverage of development and transfer of technology for all eligible countries in a measurable, reportable and verifiable manner. In this way, complementarity with other programmes is ensured.

- The body could give further specific guidance on countries' Technology Needs Assessments, and especially in carrying out the Country Programmes. Furthermore, it could review the implementation of possible Technology Agreements.

- The structure may also need to allow for sub-groups or 'panels' that provide Parties with information and services (such as technical information, or financial advice).

- For regional assistance, regional and country offices of UNEP, UNDP, or UNIDO could be mobilised.

- Better systems to manage information, and interface with key agencies within countries that are not directly represented in the negotiations (particularly from the energy, transport, and agriculture sectors) will be needed.

This conceptual framework is schematically presented in Figure 5.1, and works in selfreinforcing steps. (The orange boxes are existing or new instruments that can remain outside of the framework.) In the first step (\#1), informed by TNAs and NAMAs, the enabling environment is enhanced through policy and regulatory changes, enhancement of innovative capacity ${ }^{58}$ and better estimates of technology potential and demand. In a sequential process (but run nearly in parallel with the provision of enabling environments), the appropriate financing mechanisms and scale needs to be determined, and then secured (\#2). This is the most costly step for public finance and bears the most risk. Then agreements on technologies, sectors or SD-PAMs can be

${ }^{58}$ Carbon Trust (2008) has estimates of establishing innovation and diffusion centres of 40-100 US\$/year. 
made (possibly outside of this technology framework) and implementation can be agreed (\#3) ${ }^{59}$. The institutional framework (\#4) is then fully embedded and oversight is provided by the UNFCCC $^{60}$ with the objective of maximising emission reductions (and with regard to value-formoney). This 'stepped' approach is useful to inform process, it is, of course, highly stylised and the boundaries are unlikely to be so distinct.
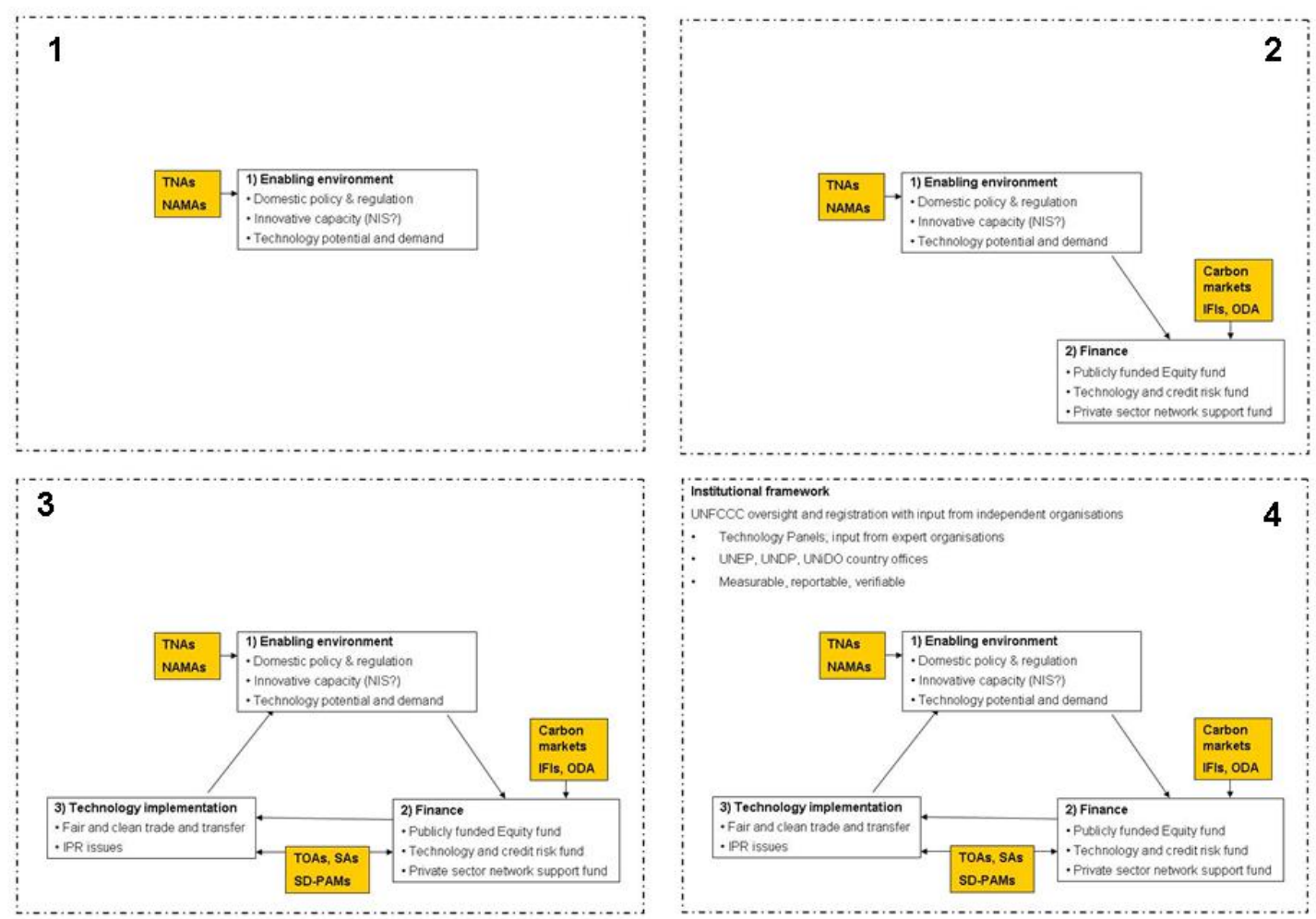

Figure 5.1 Conceptual technology framework

The framework does not imply that all technologies or countries should be addressed at once. Rather, it can be decided by Parties to address several countries, regions, or technologies first. If these early opportunities can be made into success stories, the attractiveness for future Parties to join is enhanced. However, if early efforts fail, this would likely lead to a lack of trust in the framework. It might therefore be important to initially implement it in areas with a relatively low risk of failure.

\subsection{Measuring Success}

One of the pending questions with regard to enabling environments is how their effectiveness is measured. The World Bank (2008b) provides a macroeconomic perspective of technology diffusion in the developing world. Not surprisingly, it finds that, “...since the early 1990s, technological progress in both low- and middle-income countries has increased more rapidly than in high-income countries. However, the technology gap between them remains wide.” The report highlights that innovation and invention of technologies still remains almost exclusively in the high income countries. Thus the key in the short-term will be to ensure countries' ability to absorb and adapt technologies.

59 This may need agreement on specific issues related to trade and IPR.

60 The exact place within the UNFCCC is not specified here (i.e. whether it is the SBs, the COP, the Secretariat, EGTT, etc.). 
The indicators the World Bank utilises are useful for guiding measurement in the UNFCCC process. Interesting indices include; penetration of technologies, technological achievement progress, and an achievement index. The achievement index is a statistical compilation of upwards of twenty sub-indices ranging from: number of patents, to telephone traffic outgoing, to technology exports, internet users and FDI inflows. The index offers insights into the absorption and adaptation of technology in developing countries and allows that the process is very complex and less 'mechanistic' than that depicted by most continuum schematics. This is much more in line with current insights in innovation processes that advocate that innovation depends upon interactions and knowledge and information flows between scientists in universities and other knowledge institutions, industry, and government (Lundvall, 1992; OECD, 1997). It is also consistent with the IPCC's (2000) observation that transfer encompasses “...the process of learning to understand, utilise and replicate the technology, including the capacity to choose it and adapt it to local conditions."

With the indicators for technology transfer and enabling environments still under discussion, several tools have been proposed or are being implemented that enhance the enabling environment. Ghana (2008) provides a useful list of tools that could be utilised in this area, such as ensuring a country's access to technology information, guidance on national policy, promotion of market development and transformation, market assessments, development of best practice guidance and performance standards, and staff training. More specifically, the WRI-Prayas (2007) Electricity Governance Toolkit is an example of the design and implementation of metrics to consider and improve enabling environments in one sector. Indicators are 'mapped' into policy processes, and regulatory processes, with an emphasis on environmental and social aspects of these processes. WRI (2007) stresses the importance of good governance, with reference to the principles of transparency, accountability, inclusiveness, and capacity, and also emphasises the need for policy coherence and operational cooperation across various agencies and institutions at the national and sub-national levels.

61 Nevertheless, these types of 'indicator' studies must inevitably struggle to capture technology transfer in such a rapidly evolving and increasingly globalised technology 'space'. Supply chains and corporate structures are increasingly global. Also, a great deal of technical innovation arises from using existing technologies in new ways to meet the needs of different contexts - an additional complexity not well captured in traditional indicators. 


\section{Conclusions}

Achieving climate protection goals will require deploying and diffusing a broad portfolio of technologies worldwide, most of which are either in research and development stage or already commercially available. In addition to this, technology deployment activities will require a suite of systems, institutions, markets and human capital to ensure delivery on a wider and faster scale. A review of the low-carbon technology literature reveals a valuable understanding of the general technology needs to reach mitigation targets. The costs, development pathways, policy drivers (push and pull), and overall macroeconomic impacts appear to be well enough understood to allow for the initial design of the public interventions required. Of course some uncertainty remains which requires a wide-ranging technical and financial information agenda. This, however, should not be the focus of the negotiations or hinder agreement regarding initial activities and actions that will be necessary in any case.

We have suggested the contours of how technology could be treated in the UNFCCC based on criteria derived from, and consistent with, the literature on technology and climate mitigation. A reasonable question to ask is whether such an extensive treatment of technology marks a departure from the current policy paradigm of market-based (rather than technology-focussed) instruments. This paper has not considered whether an enhanced technology framework should operate in addition to or in place of a global or regional cap-and-trade scheme. In principle, and preferably, it should function alongside a global emission reduction target (to help guide longterm investment), and progress should be in line with a shared vision on what is a sustainable global greenhouse gas emission rate. However, the literature on economics, political science, law and policy identifies difficulties of reaching international agreement on emission reductions, and free-rider incentives can provide for an unstable coalition (Barrett, 2001; Victor, 2001; Buchner and Carraro, 2005). A self-reinforcing technology framework might provide the reciprocity and solidity that an agreement based on emission reductions alone lacks. As such, the focused treatment of technology should be considered in concert with the more 'dominant' paradigm of market-based instruments in international climate policy.

It will be important to come to an agreement at the UNFCCC COP15 on the scope and underlying principles of how best to incentivise low-carbon technology development and deployment. Reaching such an agreement will require understanding the suite of available tools and actions available and palatable to the Parties. It will also require sensitivity to and a realistic assessment of the potential influence of UNFCCC agreements on private sector action. That realism should not be constrained by the perceived lack of movement in the technology area to date, given the enormous growth especially in renewable energy technology in the last decade. Businesses and governments are now also more focused on climate change and energy security issues than ever before. Despite the chaos in the financial markets, investors still appear interested in supporting technology development if they perceive a comprehensive governmental approach to hedging risk.

In the near-term the use of public financing in the areas of human and institutional capacity building and associated enabling environments is likely to provide the best focus for ensuring long-term delivery (and potentially the best value for money). The literature on technological change supports the need for focusing on institutional strengthening to overcome 'institutional inertia'. These elements of the conceptual framework are, however, difficult to quantify in terms of their direct contributions to climate change mitigation. Other national actions (i.e. design and implementation of direct deployment incentives for technologies) in the low-carbon technology area should provide excellent avenues for 'grounding' the concept of MRV. A robust framework for MRV will need to accommodate both types of interventions. 
Finally, it is important to recognize that clean energy technologies also offer enormous opportunities for reaching wider sustainable development goals in many developing countries. Implementing elements to enhance the treatment of technology in the UNFCCC will necessarily call forth new institutional structures and skills, all of which provide opportunities to 'lock-in' particular benefits, and ensure that developing countries do not get 'locked-out' of a low-carbon economy. 


\section{References}

ADB (2007). J. Carmody, D. Ritchie (2007): Investing in Clean Energy and Low-Carbon Alternatives in Asia, Manilla.

Aldy, J., P. Orszag, J. Stiglitz (2001): Climate Change: An Agenda for Global Action. Pew Centre. USA.

Aldy et al. (2003): Thirteen plus one: a comparison of global climate policy architectures. Climate Policy, 3, 373-397.

Alfsen, K. and G. Eskeland (2007): The Role of Technology in Climate Policy. Swedish Ministry of Finance.

Alic, J. and D. Mowry (2003): US Technology and Innovation Policies: Lessons for Climate Change. In proceedings from Aspen Institute. Nov. 2003. USA.

Amin, (2000): The Power of Networks: Renewable Electricity in India and South Africa. DPhil.

Andersen, S. Sarma, Madhava, and K. Taddonio (2007): Technology Transfer for the Ozone Layer: Lessons for Climate Change. Earthscan, London, UK. 2007.

Anderson, D (2006): Costs and Finance of Abating Carbon Emissions in the Energy Sector. Imperial College, UK.

Arrow, K. (1962): The Economic Implications of Learning by Doing, Review of Economic Studies, 29: 155-73.

Arthur, W.B. (1989): Competing Technologies, Increasing returns, and Lock-in by Historical Example. The Economic journal. Vol 99 (394).

Bagwell, K., and R.W. Staiger (1999): An economic theory of GATT. The American Economic Review 89(1): 215-248.

Baron R. (2007): Sectoral Approaches to greenhouse Gas Mitigation. OECD. Paris.

Baron, R., I. Barnsley and J. Ellis (2008): Options for Integrating Sectoral Approaches into the UNFCCC. OECD AIEG. Paris.

Barrett, S. (2001): Towards a Better Climate Treaty. Policy Matters 01-29, Washington, DC: AEI Brookings Joint Center for Regulatory Studies.

Barton, J. (2007): Intellectual Property and Access to Clean Energy technologies in Developing Countries. Draft. ICTSD. Issue paper 2.

Baumert, K., O. Blanchard, S. Llosa, and J.F. Perkaus (eds) (2002): Building on the Kyoto Protocol: Options for Protecting the Climate. World Resources Institute, Washington, DC [available at http://climate.wri.org/pubs_pdf.cfm?PubID=3762].

Baumert, K., and H. Winkler (2005): SD-PAMs and international climate agreements. In: R. Bradley, K. Baumert, J. Pershing (eds), Growing in the Greenhouse: Protecting the Climate by Putting Development First, World Resources Institute, Washington, DC, 15-23.

Bazilian, M., Roques, F. (eds.) (2008) Analytical Methods for Energy Diversity and Security, Elsevier Science. Amsterdam.

Bell, M., and K. Pavitt (1993): Technological Accumulation and Industrial Growth: Contrasts between Developed and Developing Countriies Industrial and Corporate Change 2:157 $-210$

Benedick, R.E. (2001): Striking a New Deal on Climate Change. Issue in Science and Technology. Fall: 71-76. 
Bergek, A., S. Jacobsson, B. Carlsson, S. Lindmark, and A. Rickne (2008): Analyzing the functional dynamics of technological innovation systems: A scheme of analysis. Published in Research Policy, 37(3), 407-429

Betz, R. and M. Sato (2006): Emissions trading: lessons learnt from the 1st phase of the EU ETS and prospects for the 2nd phase. Climate Policy 6, pp351-359.

Blair, T. (2008): Breaking the Climate Deadlock, The Climate Group. London.

Boeters, S. (2007): Post-2012 Climate Scenarios. MNP Report 500114006/2007. The Netherlands.

Bozeman, B. (2000): Technology transfer and public policy: a review of research and theory. Research Policy 29:627-655.

Bradley, R., K. Baumert, B. Childs, T. Herzog and J. Pershing (2008): International Sectoral Cooperation on Climate Change.

Bradley, R., and J. Pershing (2005): Introduction to sustainable development policies and measures. In: R. Bradley,K. Baumert, J. Pershing (eds), Growing in the Greenhouse: Protecting the Climate by Putting Development First, World Resources Institute, Washington, DC, 1-14.

Braczyk, H-J., P. Cooke and M. Heidenreich (1998): Regional innovation systems: the role of governance in a globalized world. London: UCL Press.

Brewer, T. (2007): US Climate Change Policies and International Trade Policies. Georgetown University, USA.

Brown, M. and J. Chandler (2007): Carbon Lock-in. US ORNL ORNL/TM-2007/124.

Bruckner T., O. Edenhofer et al. (2007): Robust Options for Decarbonisation: Background Paper on Energy Security for Potsdam Nobel Meeting. October 2007, Germany.

Bruijn T. de and A. Tukker (2002): Partnership and leadership: building alliances for a sustainable future. Dordrecht: Kluwer; 2002.

Buchner, B., and C. Carraro (2005): Economic and environmental effectiveness of a technologybased climate protocol. Climate Policy 4 (3): 229-248.

Caplan, A., R. Cornes and E. Silva (2003): An Ideal Kyoto Protocol: EmissionTrading, Redistributive Transfer and Global Participation. Oxford Economic Papers,55, 216 - 234.

Carbon Trust (2008): Low-Carbon Technology Innovation and Diffusion Centres. Carbontrut.co.uk. London

Carlsson, B. and S. Jacobsson (1997): In search of a useful technology policy-general lessons and key issues for policy makers. In: Carlsson, B. (Ed.), Technological Systems and Industrial Dynamics. Kluwer Press, Boston, pp. 299-315.

Climate Works (2008): accessed at: http://www.catalystproject.info//

Clarke, L. et. al. (2006): Synthesis and Assessment product Part 2.1. US CCSP, USA

Cofala J, M. Amann, F. Gyarfas, W. Schoepp, J.C. Boudri, L. Hordijk, C. Kroeze, J.F. Li, D. Lin, T.S. Panwar and S. Gupta (2004): Cost-effective control of $\mathrm{SO}_{2}$ emissions in Asia. Journal of Environmental Management 72(3) 149-161.

Coninck, H.C. de, S. Bakker, M. Junginger, O. Kuik, E. Massey and B. van der Zwaan (2007): International technology-oriented agreements to address climate change. WAB report (500102013), published by MNP: Bilthoven, Netherlands.

Coninck, H.C. de, C. Fischer, R. Newell, and T. Ueno (2008a): International Technologyoriented Agreements to Address Climate Change. Energy Policy 35, 335-356. 
Coninck, H. de, F. Haake and N. van der Linden (2008b): Technology transfer in the Clean Development Mechanism. Climate Policy 7 (5), pp. 443-455.

Cooke P., M. Gomez Uranga and G. Etxebarria (1999): Regional innovation systems: institutional and organisational dimensions. Research Policy; 26: 475-491.

Cool Earth (2008): Ministry of Economy, Trade and Industry, Government of Japan. www.meti.go.jp.

Copeland, B. and M.S. Taylor (2005): Free Trade with Global Warming: A Trade Theory View of Kyoto Protocol. Journal of Environmental Economics and Management, 49, 205 234.

Copenhagen Climate Council (2008): accessed at: http://copenhagenclimatecouncil.com.

Das, A. et. al. (2007): ACROPOLIS: International collaboration in the Field of Energy Modelling to Support GHG Mitigation Policies. Energy Policy (35) issue 2. Elsevier.

David, P. (1975): Technical Choice, Innovation, and Economic Growth. Cambridge University Press.

De Boer, Y. (2008): Address at: Forum on climate change and science and technology \& innovation Beijing. PR China, 24 April.

Deacon, R. and P. Murphy (1997): The Structure of an Environmental Transaction: The Debtfor-Nature Swap. Land Economics 73(1):1-24.

Elzen, M.G.J den (2003): FAIR 2.0. RIVM report 550015001/2003. Netherlands.

Elzen, M.G.J. den, P.L. Lucas and A. Gijesen (2007): Exploring European countries' emission reduction targets, abatement costs and measures needed under the 2007 EU reduction objectives. Netherlands Environment Analysis Agency. NL. MNP Report 500114009/2007

Dodgson, M., and J. Bessant (1996): Effective Innovation Policy: A New Approach. International Thomson Business Press, London.

Dosi, G. (1982): Technological paradigms and technological trajectories: a suggested interpretation of the determinants and directions of technical change. Research Policy;11:147162.

Dosi G, R.R. Nelson and S.G. Winter (2000): The nature and dynamics of organizational capabilities. Oxford: Oxford University Press.

Dubash, N., R. Bradley (2005): Pathways to rural electrification in India: are national goals also an international opportunity? In: R. Bradley, K. Baumert , J. Pershing (eds), Growing in the Greenhouse: Protecting the Climate by Putting Development First, World Resources Institute, Washington, DC.

EC (1999): Economic Evaluation of Quantitative Objectives for Climate Change. Ecofys, NTUA. Brussels.

EC (2003a): WETO 2030. Brussels

EC (2005): Analysis of Post-2012 Climate Policy Scenarios. EU JRC. Italy.

EC (2005b): Towards a Post-2012 Climate Change regime. DG Environment. Brussels.

EC (2007b): A European Strategic Energy technology Plan. Brussels. COM(2007) 723 Final.

EC (2007c): Impact Assessment. SEC (2008) 85. Brussels.

EC (2007d): Technology Map SEC(2007) 1510. Brussels

EC(2007e): Capacities Map SEC(2007) 1511. Brussels 
Edenhofer, O., K. Lessmann, C. Kemfert, M. Grubb and J. Köhler (2006): Induced Technological Change: Exploring its Implications for the Economics of Atmospheric Stabilization: Synthesis Report from the Innovation Modelling Comparison Project. The Energy Journal, Special issue, IAEE.

Egenhofer, C., L. Milford et al (2007): Low-Carbon technologies in the Post-Bali period. ECP report No. 4, Brussels.

EIB (2007): Guide to Financing Projects from European Technology Platforms - Debt and Grants'. Luxembourg.

Ellerman, A.D. and A. Decaux (1998): Analysis of Post-Kyoto CO 2 emissions trading Using Marginal Abatement Curves, MIT Joint Program on the Science and Policy of Global Change. Report 40, Cambridge MA

Ellis, J., R. Baron and B. Buchner (2007): SD-PAMs: What, When, Where and How? International Energy Agency. Paris.

ESMAP (2008): accessed at http://www.esmap.org.

European Union, Directorate General External Policies of the Union (2007): What contribution can trade policy make towards combating climate change?

Finus, M. and E. Ierland, E. (2006): Stability of Climate Coalitions in a Cartel Formation Game. Economics of Governance. Vol 3. Springer berlin.

Fisher, B.S. (1996): An Economic Assessment of Policy Instruments for Combating Climate Change. In James P. Bruce, Hoesung Lee, and Erik F. Haites, eds, Climate Change 1995: Economic and Social Dimensions of Climate Change. Cambridge Press.

Fisher, C. and R. Morgenstern (2005): Carbon Abatement Costs. RFF, Washington, D.C.

Fisher, J. C. and R.H. Pry (1971): A Simple Substitution Model of Technological Change. Technological Forecasting and Social Change, 3: 75-88.

Fisher M. (2001): Innovation, knowledge creation and systems of innovation. Annals of Regional Science; 35(2):199-216.

Forsyth, T. (2005): Enhancing climate technology transfer through greater public-private cooperation: Lessons from Thailand and the Philippines. Natural Resources Forum 29, pp. 165-176.

Forsyth, T. (2007): Promoting the "development dividend" in climate technology transfer: can cross-sector partnerships help? World Development 35 (10): 1684-1698.

Foxon, T. J. (2002): Technological and institutional 'lock-in' as a barrier to sustainable innovation. International Summer School on Innovation for Sustainable Development: Institutions, Incentives and Economic Policy, Seeon, Germany, September 2002, available at http://www.iccept.ic.ac.uk/public.html

Freeman, C. (1992): The Economics of Hope. Pinter Publishers, London, New York.

Freeman, C. (1997): The Political Economy of the Long-Wave. In A.Tylecote (ed).

Fukuda-Parr, S., and C. Lopes (2001): Capacity for Development: New Solutions to Old Problems. Publisher: Earthscan/ UNDP.

G8 (2008): G8 Summit Leader's Declaration. Toyako, Japan.

Gallagher, K.S. (2006): Limits to leapfrogging in energy technologies? Evidence from the Chinese automobile industry. Energy Policy 34:383-394.

Geels, F. (2004): From sectoral systems of innovation to socio-technical systems: Insights about dynamics and change from sociology and institutional theory. Research Policy 33: 897920. 
GEF (2008): Elaborating a Strategic Programme to Scale-up the Level of Investment in Environmentally Sound Technologies. Washington, DC

Ghana (2008): Proposal on Options for Effective Mechanisms and Enhanced Means for Technology Development and Transfer. Submission to AWG-LCA. Bonn.

Global Leadership for Climate Action (GLCA) (2008): Framework for a Post-2012 Agreement on Climate Change: 2008 Update.

Goldstein, J.S. (1991): Reciprocity in Superpower Relations: An Empirical Analysis. International Studies Quarterly, Vol. 35, No. 2, (Jun., 1991), pp. 195-209.

Grubb, M. (2004): Technology Innovation and Climate Change Policy. Keio Journal of Economics, Japan.

Grubb (2007): Climate Change Impacts, Energy and Development. World bank Conference on Development Economics. USA.

Grubler, A., and N. Nakicenovic (1991): Long Waves, Technology Diffusion, and Substitution. Review, 14, 313-342.

Grübler, A. (1998): Technology and Global Change. Cambridge University Press: New York, 1998.

Grübler, A. and N. Nakicenovic (1990): Diffusion of Technologies and Social Behavior. Berlin: Springer.

Grübler, A. and N. Nakicenovic (1996): Decarbonizing the global energy system. Technol. Forecast. Social Change 1996, 53 (1), 97-110.

Grübler, A., N. Nakicenovic and D.G. Victor (1999): Dynamics of energy technologies and global change. Energy Policy 1999, 27 (5), 247-280.

Guay, B., J. Corfee-Morlot and K. Larsen (2008): Measurement Reporting and Verification of Mitigation Support. AIEG OECD/IEA. Paris.

Gupta, S., D.A. Tirpak, N. Burger, J. Gupta, N. Höhne, A.I. Boncheva, G.M. Kanoan, C. Kolstad, J.A. Kruger and E. Haites (2007): Estimates of Investment and Financial Flows to 2030. UNFCCC Vienna Dialogue workshop, Austria.

Hall J, and R. Kerr (2003): Innovation dynamics and environmental technologies: the emergence of fuel cell technology. Journal of Cleaner Production 2003; 11:459-471.

Hard, M. (1993): Beyond Harmony and Consensus. Science, Technology \& Human Values, Vol. 18, No. 4, 408-432.

Harmelink, M., L. Nilsson, R. Harmse (2008): Theory-Based policy Evaluation of 20 Energy Efficiency Instruments. Energy Efficiency 1:131-148. Springer.

Heaton, G.R., R.D. Banks, and D. W. Ditz (1994): Missing Links: Technology and Environmental Improvement in the Industrializing World. World Resources Institute, Washington, DC.

Hekkert, M.P. and S.O. Negro (2008): Functions of innovation systems as a framework to understand sustainable technological change: Empirical evidence for earlier claims, Technological Forecasting and Social Change.

Henderson R.M. and K.B. Clark (1990): Architectural innovation: the reconfiguration of existing product technologies and the failure of established systems. Administrative Science Quarterly;35:9-30.

Hinostroza, M. C.C. Cheng and X. Zhu (2007) Potentials and barriers for End-Use Energy Efficiency Ander programmatic CDM. CD4CDM.

Hoff, T. (2007): Changing Research Center's Approach to Energy Innovation. Presentation at SET session. 
Hoel, M. (1999): Should a Carbon tax be Differentiated Between Sectors? Journal of Public Economics, Elsevier.

Höhne, N., J. Harnisch, G.J.M. Phylipsen, K. Blok, C. Galleguillos (2003): Evolution of commitments under the UNFCCC: Involving newly industrialized economies and developing countries. Research report 20141 255. UBA-FB 000412, German Federal Environmental Agency, Berlin, Germany, available.

Höhne, N., D. Phylipsen, S. Ullrich, K. Blok, (2005): Options for the second commitment period of the Kyoto Protocol. Climate Change 02/05, ISSN 1611-8855, prepared by Ecofys for the German Federal Environmental Agency, Berlin, Germany.

Höhne, N. (2006): Comparison of International Climate Policy Approaches for Post 2012. KyotoPlus - Papers.

Höhne, N., D. Phylipsen and S. Moltmann (2007): Factors underpinning future action - 2007 update. Report for the Department for Environment Food and Rural Affairs (DEFRA), United Kingdom, prepared by Ecofys.

Höhne, N. and S. Moltmann (2008): Linking National Climate and Sustainable Development Policies with the Post-2012 Climate Regime: Proposals in the Energy Sector for Brazil, China, India, South Africa, Indonesia, South Korea and Mexico. Draft version, November 2006, Ecofys, Cologne, Germany.

Hughes, T.P. (1983): Networks of Power. Baltimore, John Hopkins Press.

Hughes, T.P. (1989): American Genesis - A Century of Invention and Technological Enthusiasm $1870-1970$.

IEA (1999): IEA, World Energy Outlook 1999 Insights: Looking at Energy Subsidies - Getting the Prices Right. 1999.

IEA (2000): Energy Technology and Climate Change; A Call to Action. Paris.

IEA (2001): Technology Without Borders. Paris.

IEA (2004): Renewable Energy: Market and Policy Trends. Paris.

IEA (2005): Deploying Climate Friendly technologies Through Collaboration with Developing Countries. Paris.

IEA (2005b): Evaluating Energy Efficiency Policies and measures. IEA IA-DSM, Paris.

IEA (2006): World Energy outlook 2006. Paris.

IEA (2007): World Energy Outlook 2007. Paris.

IEA (2008): World Energy Outlook 2008. Paris.

IEA (2008a): Energy Technology Perspectives. Paris.

IEA (2008b): Energy Efficiency Policy Recommendations. Paris

IEA (2008c): Deploying Renewables: Principles for Effective Policies.

IEI (1988): Energy for a Sustainable World. Wiley Eastern Limited.

IIASA (2007): TNT Programme. http://www.iiasa.ac.at/Research/TNT/.

IISD (International Institute for Sustainable Development) (2005): Which Way Forward? Issues in Developing an Effective Climate Regime after 2012. IISD, Winnipeg, Canada.

IPCC (2000): Methodological and Technological Issues in Technology Transfer. Bonn.

IPCC (2007) Fisher, B., Nakicenovic, N., Alfsen, K., Corfee Morlot, J., De la Chesnaye, F., Hourcade, J.-C., Jiang, K., Kainuma, M., La Rovere, E., Matysek, A., Rana, A., Riahi, K., Richels, R., Rose, S., Van Vuuren, D. P. and Warren, R., (2007): Issues related to 
mitigation in the long-term context. In Metz, B. and Davidson, O., IPCC Fourth Assessment Report. Report of Working Group III Mitigation. Cambridge University Press, Cambridge.

ISET (2004): EXTOOL Project. (http://www.iset.uni-kassel.de/extool/).

Jaffe, A., R. Newell and R. Stavins (2001): Technological Change and the Environment Discussion Paper. 00-47REV. RFF, USA.

Jacobsson, S. and V. Lauber (2006): The politics and policy of energy system transformation explaining the German diffusion of renewable energy technology. Energy Policy 34, 256-276.

Jamasb, T. and J. Kohler (2007): Learning Curves for Energy Technology: A Critical Assessment. In Delivering a Low Carbon Electricity System: Technologies, Economics and Policy, Ed. M. Grubb, T. Jamasb, and M. Pollitt. Cambridge: Cambridge University Press, Forthcoming. Available online at (accessed 30 Nov 2007).

Karani, P. (2001): Constraints for activities implemented jointly (AIJ) technology transfer in Africa. Renewable Energy 22, pp. 229-234.

Kemfert, C. (2003): Climate Coalitions and International Trade. Energy Policy. Elsevier.

Kemfert, C. (2004): Games of Climate Change with International Trade. Environmental and Resource Economics. Springer.

Kemp R. (1997): Environmental policy and technological change: a comparison of the technological impact of policy instruments. Cheltenham: Edward Elgar.

Keohane, R.O. (1986): Reciprocity in International Relations. International Organization 40(1), 1-27.

Klein-Voolthuis, R., M. Lankhuizen and V. Gilsing, V. (2005): A system failure framework for innovation policy design, Technovation, 25. 609-619.

Kline, D., L. Vimmerstedt and R. Benioff (2004): Clean Energy Technology; Mitigation and Adaptation Strategies for Global Change. Volume 9, Number 1, 2004 , pp. 1-35(35).

Kohler, J. M. Grubb, D. Popp and O. Edenhofer (2006): The Transition to Endogenous Technical Change in Climate-Economy Models: A Technical Overview to the Innovation Modeling Comparison Project. Energy Policy.

Kranzberg, M. (1986): The Technical Elements in International Technology Transfer: Historical Perspectives. In The Political Economy of International Technology Transfer. J. R. McIntyre, D.S. Papp, (eds.), Quorum Books, New York, pp.31-46.

Laitner, S. (2006): Improving the Contribution of Economic Models in Evaluating Energy and Climate Change Mitigation Policies. Working Paper, ACEEE, USA.

Lall, S. (1992): Technological capabilities and industrialization. World Development 20 (2): 165-186.

Levine M.D., H.Geller, J. Koomey, S. Nadel and L. Price (1992): Electricity End-Use Efficiency: Experience with Technologies, Markets, and Policies Throughout the World. Berkeley, CA: Lawrence Berkeley Natl. Lab.

Lewis, J. and E. Diringer (2007): Policy-Based Commitments in a Post-2012 Climate Framework. PEW Center on Global Climate Change. Washington, DC.

Lopes, C. and T. Theisohn (2003): Ownership, Leadership and Transformation: Can We Do Better for Capacity Development? Earthscan Publications Ltd.

Lundvall, B. (1992): National Systems of Innovation: Towards a theory of innovation and interactive learning. Pinter, London, UK. 
MacGill, I. F. (2008): Assessing Australia's Sustainable Energy Technology Options: Key Issues, Uncertainties, Priorities and Potential Choices. Forthcoming in Asia Pacific Journal of Environmental Law.

MacGill, I.F., H.R. Outhred, and K. Nolles (2006): Some design lessons from market-based greenhouse regulation in the restructured Australian electricity industry. Energy Policy, 34 (1), pp. 11-25.

Magnusson, T., G. Lindström and C. Berggren (2003): Architectural or modular innovation? Managing discontinuous product development in response to challenging environmental performance targets. International Journal of Innovation Management 2003;7(1):1-26.

Malmborg, F. von (2007): Stimulating learning and innovation in networks for regional sustainable development. Journal of Cleaner Production, 15, 1730-1741.

Mandelson (2006): How trade can be part of the climate change solution. Speech on 18 December 2006.

Marlay, R. (2008): Roadmaps From the U.S. Climate Change Technology Program Strategic Plan. USCCTP. Delivered at IEA. Paris.

Martinot, E., J.E. Sinton, and B.M. Haddad (1997): International Technology Transfer for Climate Change Mitigation and the Cases of Russia and China. In Annual Review of Energy and Environment, Vol. 22. R. H. Socolow, D. Anderson, J. Harte, (eds.), Annual Reviews Inc., Palo Alto, CA, pp. 357 - 401.

Maskus, K. (2004): Encouraging International transfer of technology. ICTSD Issue paper 7.

Mckinsey Global Institute (2008): The Case for Investing in Energy Productivity. Mckinsey and Company, San Francisco.

MDB (2008): Joint Report to the G8 on the Implementation of the Clean Energy Investment Framework (CEIF) and Their Climate Change Agenda Moving Forward July 2008. African Development Bank, Asian Development Bank, European Bank for Reconstruction and Development, European Investment Bank, Inter-American Development Bank and the World Bank.

Metz, B., M. Berk, M. den Elzen, B. de Vries and D. van Vuuren (2002): Towards an equitable global climate change regime: compatibility with Article 2 of the Climate Change Convention and the link with sustainable development'. Climate Policy 2(2-3), 211-230.

Milford (2007): A New Geometry of Complementary Climate Technology Solutions. CEG Working Paper, USA.

Misa, T. J. (1994): Controversy and closure in technological change: constructing "steel". In Bijker, W. E. and Law, J., (Eds.), Shaping technology building society: studies in sociotechnical change, The MIT Press, Cambridge Ma, pp. 109-139.

Moreira, J.R., L.A.H. Nogueira and V. Parente (2005): Biofuels for transport, development and climate change: lessons from Brazil. In: R. Bradley, K. Baumert, J. Pershing (eds), Growing in the Greenhouse: Protecting the Climate by Putting Development First, World Resources Institute, Washington, DC.

Morgan, T. (2007): Energy Subsidies: Their Magnitude, How they Affect Energy Investment and Greenhouse Gas Emissions, and Prospects for Reform. UNFCCC paper.

Mukherjee, V. and D. Rübbelke (2007): Global Climate Change,Technology Transfer and Trade with Complete Specialization. NOTA DI LAVORO 114.2006.

Muller, F. (2005): Options for Future Climate Policy: Transatlantic perspectives. INTACT. SWP. Berlin

Murphy, L. and P. Edwards (2003): Bridging the Valley of Death: Transitioning from Public to Private Sector Financing. NREL, USA. 
Mytelka, L. (2007): Technology Transfer Issues in Environmental Goods and Services: An Illustrative Analysis of Sectors Relevant to Air-pollution and Renewable Energy. ICTSD Trade and Environment Series Issue Paper No. 6 International Centre for Trade and Sustainable Development, Geneva, Switzerland.

Nakhooda, S., S. Dixit and N. Dubash (2007): Empowering People: A Governance Analysis of Electricity - India, Indonesia, Thailand and the Philippines. World Resources Institute, Washington DC.

Nakicenovic, N. (1997): Technological Change and Diffusion as a Learning process. Perspectives in Energy, Vol. 4, Number 2. Moscow.

Nakicenovic, N., and R. Swart (2000): Special Report on Emissions Scenarios. Cambridge University Press, Cambridge, United Kingdom.

Nelson R.R. and S.G. Winter (1982): An evolutionary theory of economic change. Cambridge, MA: Harvard University Press.

Ng, Wei-Shiuen, Lee Schipper (2005): China Motorization Trends: Policy Options in a World of Transport Challenges. In Bradley, Baumert et al. (2005). World Resources Institute, Washington, DC.

Norberg-Bohm, V. (2000): Creating Incentives for Environmentally Enhancing Technological Change. Lessons from 30 Years of U.S. Energy Technology Policy. Technological Forecasting and Social Change 65: 125-148.

Nordhaus, W. (1969): An Economic Theory of technological Change. American Economic review. 51.

Nordhaus, R. (2003): What is the Role of Product Efficiency Standards Under a Cap and Trade Programme? In proceedings from Aspen Institute Nov. 2003. USA.

Nordhaus (2007): The Challenge of Global Warming: Economic Models and Environmental Policy. Yale University Working Paper, USA.

Noro, H. (2007): Technology Transfer Financing to Developing Countries. Ministry of Environment, Finland.

NREL (2008): accessed at: http://www.nrel.gov/technologytransfer. Golden, CO. USA.

Obersteiner, M. and C. Azar (2002): Biomass Energy, Carbon Removal and Permanent Sequestration. IISAS, Vienna.

Ockwell, D. and J. Watson (2007): UK-India Collaboration to identify the barriers to the transfer of low carbon energy technology. UK DEFRA.

OECD (1997): National Innovation Systems. OECD, Paris, France.

OECD (2002): Defining and Measuring Environmentally Harmful Subsidies in the Energy Sector. Paris.

Ott, H. (2005): Models for Climate Technology Agreements. Wuppertal Institute for Climate, Environment and Energy. Germany.

Ott, H. (2007): Climate Policy Post-2012: A Roadmap. Tallberg Forum.

Outhred, H. (2008): The Smart Grid, getting the Incentives Right. National Smartgrids Summit. UNSW, Australia.

Pacala, S. and R. Socolow (2004): Stabilization Wedges: Solving the Climate Problem for the Next 50 Years with Current Technologies. Science, Vol. 305, Issue 5686, pp. 968-972, 13 August 2004.

Pacey, A. (1983): The Culture of Technology. MIT Press. 
Perez, C. (1983): "Structural change and assimilation of new technologies in the economic and social systems" Futures, Vol. 15, No 4, October, pp. 357-375. In Italian in P. Bisogno ed., Paradigmi Tecnologici: Saggi Sull Economia del Progresso Tecnico, Prometheus No. 2, 1985, Milan, pp. 155-186.

Pew Center on Global Climate Change (2005): Beyond 2012, International climate efforts, report of the Climate Dialogue at Pocantico. Nov 2005

Philibert, C. (2003): Technology Innovation, Development and Diffusion. OECD/IEA Information Paper, Paris.

Philibert, C., (2004): International Energy Technology Collaboration and Climate Change Mitigation, OECD/IEA Information Paper, Paris.

Philibert (2005): The Role of Technological Development Policies in a Post-Kyoto Climate Regime. Climate Policy (5) 291-308.

Philibert, C. (2007): Technology Penetration and Capital Stock Turnover. IEA, OECD, Paris.

Pizer, W. and D. Popp (2007): Endogenizing Technological Change. RFF, Washington, D.C.

Potsdam Memorandum (2007): Global Sustainability: A Nobel Cause. Germany.

Reddy M.N. and L.M. Zhao (1990): International technology transfer: a review. Res. Policy.

Reddy, A.K.N (1991): Barriers to improvements in energy efficiency. Energy Policy 19 (10), 953-961.

REN21 (2008): 2007 Global Status Report. REN 21. Paris. http://www.ren21.net

Riahi, K. (2006): Scenarios of long-term socio-economic and environmental development under climate stabilization. Technological Forecasting \& Social Change. Elsevier.

Rip, A. and R. Kemp (1998): Technological Change. In Human Choice and Climate Change, Vol. 2: Resources and Technology. S. Rayner, E.L. Malone , \{eds.), International Energy Agency, Batelle Press, Cheltenham, UK.

Robinson, R. D. (1991): The International Communication of Technology: A Book of Readings. Taylor and Francis, New York.

Rosenberg, N. (1976): Perspectives on Technology. Cambridge University Press, Cambridge.

Rosenberg, N. (1982): Inside the Black Box: Technology and Economics. Cambridge University Press, New York.

Rosenberg, N. (1994): Exploring the Black Box. Cambridge University Press.

Ruffin, R. and R. Jones (2005): International technology transfer. University of Houston, USA.

Sadler-Smith E., B. Badger (1998): Cognitive style, learning and innovation. Technology Analysis \& Strategic Management;10(2):247-265.

Sanden, B. and C. Azar (2004): Near-Term technology Policies for Long-Term Climate Targets. Energy Policy 33:12. Elsevier.

Schmidt, J. (2006): Sector-Based Approaches top the post-2012 Climate Change Policy Architecture.

Schrattenholzer (2003): Deployment Polices Using Learning. IEA Seminar on Experience Curves, January.

Schumpeter, J.A. (1934): The Theory of Economic Development: An Inquiry into Profits, Capital, Credit, Interest, and the Business Cycle. (1949 ed.). Cambridge, MA: Harvard University Press.

Seres, S. (2007): Analysis of Technology Transfer in CDM Projects. Prepared for UNFCCC. Bonn. 
Solow, R. (1957): Technical Change and the Aggregate Production Function The Review of Economics and Statistics, Vol. 39, No. 3 (Aug., 1957), pp. 312-320.

South Africa (2006): Sustainable Development Policies and Measures: a strategic approach for enhancing the climate regime post-2012: Presentation at 2nd UNFCCC Dialogue, http://unfccc.int/files/meetings/dialogue/application/vnd.mspowerpoint/cop12_dial_sa.pps\#2.

Stavins (1997): Policy Instrument for Climate Change. University of Chicago legal Forum. USA.

Stern (2008): Key Elements of a Global Deal on Climate Change. LSE, UK.

Stern, N., S. Peters, V. Bakhshi, A. Bowen, C. Cameron, S. Catovsky, D. Crane, S. Cruickshank, S. Dietz, N. Edmonson, S.-L. Garbett, L. Hamid, G. Hoffman, D. Ingram, B. Jones, N. Patmore, H. Radcliffe, R. Sathiyarajah, M. Stock, C. Taylor, T. Vernon, H. Wanjie, and D. Zenghelis (2006): Stern Review: The Economics of Climate Change. HM Treasury, London.

Stiglitz, J. (1999): Public private technology Partnerships, American Behavioral Scientist. Vol. 43, No. 1, 52-73 (1999).

Stirling, A. (1994): Diversity and ignorance in Electricity Supply Investment. Energy Policy 22:3. Elsevier.

Storey, P. (2007): Mobilising capital for technology transfer. UNFCCC COP 13 EGTT/CTI side event, Bali.

Strachan (2007): Final Report on DTI-DEFRA Scenarios and Sensitivites. Policy Studies Institute, DTI/DEFRA, London.

Sugiyama (2005): Governing Climate. IISD, Canada.

Tanunchaiwatana, W (2007): Evolution of Technology Transfer Activities under the UNFCCC, TNA Workshop. Bangkok.

Tidd J., J. Bessant K. Pavitt (1997): Managing innovation: integrating technological, market and organizational change. Chichester: Wiley.

Tol R.S.J., W. Lise, B. Morel (2001): Technology Development and Diffusion Incentives to Abate Greenhouse Gas Emissions. Working Paper, FEEM.

Tol, R.S.J. (2007): The Social Cost Of Carbon: Trends, Outliers And Catastrophes. FNU-144.

U.S. Office of the United States Trade Representative [USTR] (2006): Report by the United States Trade Representative on Trade-Related Barriers to the Export of Greenhouse Gas Intensity Reducing Technologies. Washington, DC: USTR.

UNCSD (2008): CSD Partnership List. Accessed 2008 on http:www.un.org.

UNDP (2005): Capacity Development Group, A Brief Review of 20 Tools to Assess Institutional Capacity. UNDP/BDP/CDG

UNDP (2008): Capacity Development Library. http://www.cpacity.undp.org.

UNEP (2004): Financial Risk Management Instruments for Renewable Energy Projects. UNEP/DTIE. Paris.

UNEP (2005): Public Finance Mechanisms to Catalyse Sustainable Energy Sector Growth. Paris.

UNEP (2006): Making it Happen: Renewable Energy Finance and Role of Export Credit Agencies. UNEP. DTIE. Paris

UNEP (2008a): Global Trends in Sustainable Energy Investment. SEFI. Paris. 
UNEP (2008b): Investing in a Climate for Change. UNEP DTIE. Paris.

UNEP (2008c): Background paper for the ministerial-level consultations; Governing Council of the United Nations Environment Programme. UNEP/GCSS.X/9.

UNEP (2008d): Global Green New Deal. Press Release. October, 22, 2008. London and Nairobi.

UNEP (2008e): Green Jobs: Towards Decent Work in a Sustainable Low-Carbon World.

UNEP Risø (2008): CDM project pipeline, consulted in October 2008: www.cdmpipeline.org.

UNFCCC (2003): Enabling Environments for Technology Transfer. UNFCCC/TP/2003/2. Bonn.

UNFCCC (2006): Innovative options for financing the development and transfer of technologies. FCCC/TP/2006/1.

UNFCCC (2006b: Synthesis Report on technology Needs. FCCC/SBSTA/2006/INF.1.

UNFCCC (2007): Dialogue Working Paper 8 on Investment Flows. Vienna.

UNFCCC (2007b): Capacity Building Activities and Needs, FCCC/SBI/2007/MISC.8.

UNIDO (2008): Annual Report 2007. Vienna.

US Department of Energy (2006): Climate Change Technology Plan. DoE PI/0005. Washington, D.C.

Uyterlinde, M.A (2006): The Contribution of CCS to a Sustainable Energy System. FP6, ECN, NL.

Van Vuuren (2007): Scenarios in the context of assessment of mitigation and adaptation. UNFCCC, Bonn.

Van Vuuren D.P., J. Cofala, H.E. Eerens, R. Oostenrijk, C. Heyes, Z. Klimont, M.G.J. den Elzen and M. Amann (2006): Exploring the ancillary benefits of the Kyoto Protocol for air pollution in Europe. In Energy Policy 34 (4): 444-460.

Van Vuuren, D.P., M.G.J. den Elzen, B. Eickhout, P.L. Lucas, B.J. Strengers, and B. Ruijven, (2006b): Stabilising greenhouse gas concentrations. Assessment of different strategies and costs using an integrated assessment framework, in Climatic Change.

Vattenfall (2007): Global Mapping of GHG Abatement to 2030. Vattenfall AB, Sweden.

Watson, R. (2007): Financing the Transition to a Low Carbon Economy. World Bank, Washington DC.

Weikard, H.P. and M. Finus (2006): The impact of surplus sharing on the stability of international climate agreements. Oxford Economic Papers. UK.

Wellington, F. and R. Bradley (2007): Scaling Up: Global Technology Deployment to Stabilize Emissions. World Resources Institute.

Welsh Larson, D., 1988. The Psychology of Reciprocity in International Relations. Negotiation Journal on the Process of Dispute Settlement 4(3): 281-301.

Wene (2003): Learning Investments for Market Transformation. IEA Seminar on Experience Curves, Paris. January.

Weyant, J.P. (ed.) (2004): EMF introduction and overview. Alternative technology strategies for climate change policy. Energy Economics Special Issue, 26: 501-755.

Wilson, T. (2008): Undermining Mitigation Technology. APEC. Australia. 
Winkler, H., R. Spalding-Fecher, S. Mwakasonda and O. Davidson (2002): Sustainable development policies and measures: starting from development to tackle climate change. In: K. Baumert, O. Blanchard, S. Llosa, J.F. Perkaus (eds), Building on the Kyoto Protocol: Options for Protecting the Climate, World Resources Institute, Washington, DC, 61-87.

Winkler, H., M. Howells and K. Baumert (2005): Sustainable Development Policies and Measures: Institutional Issues and Electrical Efficiency in South Africa. Center for Clean Air Policy, Washington, DC [available at www.ccap.org/ international/oct05.htm].

Winkler, H., Mukheibir, P., Mwakasonda, S. (2006) Electricity Supply Options, Sustainable Development and Climate Change: Case Studies for South(ern) Africa, Draft, Energy Research Centre, University of Cape Town, South Africa.

Winkler, H., M. Howells and K. Baumert (2007): Sustainable development policies and measures: institutional issues and electrical efficiency in South Africa. Climate Policy 7, 212229.

Winkler, H., N. Höhne, and M. den Elzen (2008): Methods for quantifying the benefits of sustainable development policies and measures (SD-PAMs). CLIMATE POLICY 8 (2008) 119-134.

Winner, L. (1977): Autonomous Technology. MIT Press.

Winner, L. (1997): Upon Opening the Black Box and Finding It Empty: Social Constructivism and the Philosophy of Science. Technology, \& Human Values, 1993 - JSTOR.

World Bank (2006): An Investment framework for Clean Energy and Development. Washington, D.C., USA.

World Bank (2006a): Progress Report on the An Investment Framework for Clean Energy and Development. WBG, DC.

World Bank (2008b): GEP, Technology Diffusion in the Developing World. Washington, D.C. USA

World Bank (2008a): International Trade and Climate Change. Washington, DC: USA.

World Wildlife Fund (WWF) (2008): Climate Solutions; Visions for 2050.

Yang, M. and W. Blyth (2007): Modelling Investment Risks and Uncertainties with Real Options Approach. IEA, Paris, LTO/2007/WP01.

Zaelke, D. and S. Stone (2007): Montreal protocol: lessons for Climate Change. IGSD. Delivered in COP13. Bali.

Ziman, J.M. (1968): Public Knowledge: An Essay Concerning the Social Dimension of Science. Cambridge University Press. 